\title{
Carboxylesterase 1 and Precision Pharmacotherapy: Pharmacogenetics and Nongenetic Regulators
}

\author{
(1) Lucy Her and Hao-Jie Zhu \\ Department of Clinical Pharmacy, University of Michigan, Ann Arbor, Michigan
}

Received October 17, 2019; accepted December 16, 2019

\begin{abstract}
Carboxylesterase (CES) 1 is the most abundant drug-metabolizing enzyme in human livers, comprising approximately $1 \%$ of the entire liver proteome. CES1 is responsible for $80 \%-95 \%$ of total hydrolytic activity in the liver and plays a crucial role in the metabolism of a wide range of drugs (especially ester-prodrugs), pesticides, environmental pollutants, and endogenous compounds. Expression and activity of CES1 vary markedly among individuals, which is a major contributing factor to interindividual variability in the pharmacokinetics (PK) and pharmacodynamics (PD) of drugs metabolized by CES1. Both genetic and nongenetic factors contribute to CES1 variability. Here, we discuss genetic polymorphisms, including singlenucleotide polymorphisms (SNPs), and copy number variants and nongenetic contributors, such as developmental status, genders, and drug-drug interactions, that could influence CES1 functionality and the PK and PD of CES1 substrates. Currently, the loss-of-function SNP G143E (rs71647871) is the only clinically significant CES1 variant identified to date, and alcohol is the only
\end{abstract}

potent CES1 inhibitor that could alter the therapeutic outcomes of CES1 substrate medications. However, G143E and alcohol can only explain a small portion of the interindividual variability in the CES1 function. A better understanding of the regulation of CES1 expression and activity and identification of biomarkers for CES1 function in vivo could lead to the development of a precision pharmacotherapy strategy to improve the efficacy and safety of many CES1 substrate drugs.

\section{SIGNIFICANCE STATEMENT}

The clinical relevance of CES1 has been well demonstrated in various clinical trials. Genetic and nongenetic regulators can affect CES1 expression and activity, resulting in the alteration of the metabolism and clinical outcome of CES1 substrate drugs, such as methylphenidate and clopidogrel. Predicting the hepatic CES1 function can provide clinical guidance to optimize pharmacotherapy of numerous medications metabolized by CES1.

\section{Introduction}

Carboxylesterase (CES) 1 is a phase I drug-metabolizing enzyme (DME) responsible for $80 \%-95 \%$ of total hydrolytic activity in the liver (Imai et al., 2006); it metabolizes a wide range of drugs, pesticides, environmental pollutants, and endogenous compounds, including lipid esters (Table 1). CES1-mediated metabolism can lead to the biotransformation of a pharmacologically active drug into its inactive metabolite, as exemplified by methylphenidate hydrolysis in the liver. CES1 also plays an important role in activating prodrugs since most ester-containing prodrugs are exclusively dependent on CES1 for their activation. The clinical relevance of CES1 has been well demonstrated in various clinical

This work was supported in part by the National Heart, Lung, and Blood Institute [Grant R01HL126969].

The authors state no conflict of interests.

https://doi.org/10.1124/dmd.119.089680. trials with oseltamivir, methylphenidate, and clopidogrel (Zhu et al., 2008; Tarkiainen et al., 2012; Lewis et al., 2013; Jiang et al., 2016). Recent studies have also revealed that CES1 acts as a cholesteryl ester hydrolase in lipid metabolism in human macrophages and hepatocytes and suggest CES1 as a potential drug target for the treatment of metabolic diseases, such as diabetes and atherosclerosis (Dolinsky et al., 2004; Zhao et al., 2007; Ghosh et al., 2010; Ross et al., 2010; Lian et al., 2018b).

\section{Importance of CES1 in Drug Metabolism}

CES1 plays an important role in metabolizing many clinically significant medications, especially the ester-prodrugs (Table 1). A prodrug refers to an inactive drug molecule that needs to be enzymatically biotransformed in vivo to its active metabolite to produce its intended pharmacological effect (Rautio et al., 2008). Prodrug design offers an attractive method to overcome the issue of low bioavailability for Biopharmaceutics Classifications System

ABBREVIATIONS: AA, amino acid; ACEI, angiotensin-converting enzyme inhibitor; ADHD, attention deficit hyperactivity disorder; ADP, adenosine diphosphate; AT, angiotensin; AUC, area under the curve; BCS, Biopharmaceutics Classification System; CBD, cannabidiol; CBN, cannabinol; CES, carboxylesterase; $\mathrm{Cl}$, confidence interval; CNV, copy number variation; CYP, cytochrome p450; DABE, dabigatran etexilate; DME, drugmetabolizing enzyme; FDA, Food and Drug Administration; ID, identification; LOF, loss-of-function; M1, dabigatran etexilate intermediate metabolite 1; M2, dabigatran etexilate intermediate metabolite 2; MAF, minor allele frequency; PAPI, Pharmacogenomics of Antiplatelet Intervention; PD, pharmacodynamics; PK, pharmacokinetics; PNPA, $p$-nitrophenyl acetate; SNP, single-nucleotide polymorphism; THC, tetrahydrocannabinol; UGT1A, UDP-glucuronosyltransferase family 1 member A1; VASP-PRI, vasodilator-stimulated phosphoprotein-platelet reactivity index. 
TABLE 1

List of CES1 substrates

\begin{tabular}{|c|c|c|}
\hline ACE (Angiotensin-Converting Enzyme) Inhibitor & CNS (Central Nervous System) agents & Antihyperlidpidemia agents \\
\hline Enalapril $^{a}$ & Methylphenidate & Clofibrate \\
\hline Benzapril $^{a}$ & Heroin & \\
\hline Quinapril $^{a}$ & Mepridine & Adrenal glucocorticoid \\
\hline Trandolapril $^{a}$ & Rufinamide & \\
\hline Antiviral agents & Anticancer agents & Chemical warfare agents \\
\hline Oseltamivir $^{a}$ & Capecitabine $^{a}$ & Sarin \\
\hline Sofosbuvir $^{a}$ & Irinotecan $^{a}$ & Soman \\
\hline Cholesterol & Clopidogrel & Trans-permethrin \\
\hline Fatty acid ethyl esters & Dabigatran $^{a}$ & Para-nitrophenyl valerate \\
\hline Angiotensin receptor-neprilysin inhibitor (ARNi) & Immunosuppressive agents & Others \\
\hline Sacubitril $^{a}$ & Mycophenolate mofetil $^{a}$ & Dimethyl fumarate ${ }^{a}$ \\
\hline
\end{tabular}

${ }^{a}$ Prodrugs that need CES1 activation.

(BCS) class III drug molecules. Drug molecules can be categorized into four BCS classes based on permeability and solubility, and a BCS class III substance is a hydrophilic compound with low permeability and high solubility (Shah and Amidon, 2014). In particular, hydrophilic compounds with $-\mathrm{OH}$ or $-\mathrm{COOH}$ functional groups usually have difficulty being absorbed into the body, and drug developers often mask these functional groups using an ester-prodrug design. The prodrug market has been growing: $20 \%$ of drugs approved in 2015 were prodrugs compared with $\sim 6 \%$ of all currently approved drugs (Rautio et al., 2017).

Two major assumptions behind the ester-prodrug design are that prodrugs are rapidly activated via unspecific esterases in the body and that the interindividual variability in activating a prodrug is clinically insignificant. These incorrect assumptions may have stemmed from the fact that many hydrolytic enzymes exist in the body, such as CES1, CES2, acetylcholinesterase, butyrylcholinesterase, paraoxonases, and arylesterase. However, these hydrolases differ in their tissue-specific expression, cellular localization, and, most importantly, substrate selectivity (Fukami and Yokoi, 2012). In humans, CES1 is highly abundant in the liver and expressed to a lesser extent in the lung and brain; CES1 expression is considered negligible in the human intestine, kidney, and plasma. CES1 is substrate-selective toward carboxyl esters with a large ethyl group and a small alcohol group. In comparison, CES2, another major carboxylesterase in humans, is highly expressed in the intestine, kidney, and liver and is more efficient at metabolizing compounds with a small ethyl group and a large alcohol group (Jewell et al., 2007). Numerous in vivo and in vitro studies have demonstrated the specificity of CES1, and many CES1 substrates cannot be metabolized by other esterases (Table 3).

CES1 expression and activity vary significantly among individuals (Wang et al., 2016b); this variability could result in treatment failure and unexpected adverse effects of CES1 substrate drugs. A better understanding of the genetic and nongenetic factors contributing to CES1 variability will improve the design and clinical use of many drugs that are metabolized (deactivated/activated) by CES1.

\section{Pharmacogenetics of Drug-Metabolizing Enzymes}

Traditionally, fixed-dose regimens have been used for most medications. However, different individuals taking the same dose of medication do not necessarily achieve the same drug exposure and, hence, drug response. More individualized, patient-centered dosing regimens have been developed based on a patient's characteristics, such as renal clearance, liver function, body weight, and surface area (DiPiro, 2017). In addition, genetic polymorphisms of DMEs have been found to play an important role in the response to pharmacotherapy, and pharmacogenomics has been increasingly used in the clinic to improve the efficacy and safety of drug treatment. DMEs serve to primarily detoxify digested xenobiotics through four general mechanisms: hydrolysis (e.g., carboxylesterase), reduction (e.g., carbonyl reductase), oxidation (e.g., cytochrome P450), and conjugation (e.g., UDP-glucuronosyltransferase) (Foti and Dalvie, 2016). The expression and activity of DMEs vary significantly among individuals, and studying pharmacogenomics of DMEs is one means of better understanding interindividual variability in the pharmacokinetics (PK) and pharmacodynamics (PD) of a drug. For example, the active metabolite of irinotecan, $\mathrm{SN}-38$, is primarily metabolized by the enzyme UDP-glucuronosyltransferase family 1 member A1 [(UGT1A1) enzyme] (Ando et al., 2000). If a patient carries the common UGT1A1*28 polymorphism, the decrease it causes in UGT1A1 enzymatic activity would impede the metabolism of SN38 , leading to the accrual of toxic concentrations. Accordingly, the Food and Drug Administration (FDA) recommended that patients with UGT1A $1 * 28 / * 28$ start irinotecan at a lower dose (Innocenti et al., 2004). However, given that both genetic and environmental factors contribute to DME function, we should also pay close attention to nongenetic contributors when studying the variability of DMEs.

\section{CES1 Pharmacogenetics}

Although CES1 plays a critical role in the metabolism of many clinically important medications, CES1 pharmacogenetics is understudied relative to other major DMEs [e.g., cytochrome P450 (CYPs)]. CES1 is encoded by the CES1 gene and consists of 14 exons located on chromosome 16q13-q22.1. CES1 VAR is a variation of the CES1 gene that differs in exon 1 DNA sequences and has an average minor allele frequency (MAF) of $17 \%$. Although one study claimed that CES1 VAR mRNA was undetectable (Fukami et al., 2008), an in vitro human liver study showed that the protein expressions of CES1 and CES1 VAR were not statistically different (Wang et al., 2016b). CES1P1 is a pseudogene due to a premature stop codon in exon 4 and lies tail-to-tail with CES1 (Fig. 1) (Wang et al., 2016b). Interestingly, a CES1P1 variant named CESIPI VAR is a functional coding gene with a DNA sequence identical to CES1 VAR. However, the transcription efficiency of CESIP1 VAR is only $2 \%$ of that of $C E S 1$ because of the transcription factor specificity protein 1 and the enhancer-binding protein, CCAAT-enhancer-binding protein $\alpha$, preferring to bind to the CES1 promoter over the CESIP1 $V A R$ promoter (Hosokawa et al., 2008; Yoshimura et al., 2008). Because of the existence of the CESI VAR and CESIPI VAR variants, 
four CES1/CES1P1 haplotypes can be formed (Fig. 1). In addition to these structural variations, there are over 7000 CES1 single-nucleotide polymorphisms (SNPs) registered in the National Center for Biotechnology Information SNP database, and approximately 300 of them have MAFs over $1 \%$. These common CESI variants (MAF $>1 \%$ ) are distributed in various regions of the gene, including 13 in $5^{\prime}-$ and $3^{\prime}$-untranslated regions, 14 in exons, and 308 in introns. Of the exonic SNPs, 12 are nonsynonymous SNPs, and two are synonymous SNPs. In the following section, we discuss the clinical findings and mechanistic bases of functional CES1 variants identified to date.

\section{Pharmacogenetics of the First Loss-of-Function CES1 Variant G143E (rs71647871)}

In SNP notation, G143E indicates an amino acid change from glycine to glutamic acid at amino acid position 143. G143E is also termed $428 \mathrm{G}>\mathrm{A}$, indicating that the nucleotide guanine is changed to adenine at position 428 of the CES1 mRNA (DiPiro, 2017). The MAF of G143E is $3.7 \%, 4.3 \%$, and $2 \%$, in White, Hispanic, and African American populations, respectively, whereas the SNP is extremely rare in Asian populations (Zhu et al., 2008; Suzaki et al., 2013a).

G143E is a nonconservative amino acid substitution located near the active-site triad residues of CES1 (serine 221, glutamic acid 354, and histidine 468). Serine hydrolases share similar catalytic mechanism involving 1) nucleophilic attack from oxygen in the serine residue on a substrate ester bond, 2) formation of a tetrahedral intermediate wherein the deprotonated oxygen is stabilized via an oxyanion hole, 3 ) formation of an acyl-enzyme intermediate, and 4) water-catalyzed hydrolysis (Satoh and Hosokawa, 2006). For CES1 to maintain its enzymatic function, the catalytic triad and oxyanion hole need to be conserved (Zhu et al., 2008; Arena de Souza et al., 2015). The change from glycine (hydrophobic residue) to glutamic acid (electrostatic residue) at codon 143 disrupts the hydrophobicity needed for the oxyanion hole (Gly 141131), resulting in a complete loss of function of CES1. The G143E is only CES1 SNP that has been subjected to in vitro kinetics studies in which the variant exhibited null catalytic activity on all tested CES1 substrates except for oseltamivir (Table 2). The $V_{\max }$ of G143E on oseltamivir hydrolysis was $37 \mathrm{nmol} / \mathrm{min}$ per milligram with catalytic efficiency of $17.2 \mu \mathrm{l} / \mathrm{min}$ per milligram protein — this was approximately $16 \%$ of wild-type CES1 catalytic efficiency (Zhu and Markowitz, 2009).

Discovery of G143E and Its Impacts on Methylphenidate PK and PD. G143E is the first loss-of-function (LOF) variant known for CES1 and was originally discovered in a methylphenidate (Ritalin) PK study in healthy volunteers. Methylphenidate is a central nervous system stimulant and the most commonly prescribed medication for attention deficit hyperactivity disorder (ADHD) treatment. Methylphenidate has high abuse potential when used with alcohol (COTEMPLA XR-ODT(TM), 2017). Its drug product comes as a racemic mixture of $d$ and $l$-methylphenidate hydrochloride; $d$-methylphenidate is approximately 10 times more pharmacologically potent than $l$-methylphenidate (Heal and Pierce, 2006).

Methylphenidate is metabolized by de-esterification via CES1 to ritalinic acid, an inactive metabolite that accounts for approximately $80 \%$ of the recovered dose in human urine (Fig. 2) (Laizure et al., 2013; COTEMPLA XR-ODT(TM), 2017). In 2007, a prospective single-dose $(0.3 \mathrm{mg} / \mathrm{kg})$ PK study was conducted in 20 healthy volunteers to examine the drug-drug interaction (DDI) between methylphenidate and alcohol (Patrick et al., 2007). During this study, the researchers unexpectedly found a participant that showed significantly elevated pharmacokinetic parameters [e.g., area under the curve (AUC), $\mathrm{C}_{\max }$ ] of methylphenidate. Specifically, $d l$-methylphenidate $\mathrm{C}_{\max }$ was seven times higher and $l$-methylphenidate $C_{\max }$ was 100 -fold higher in this poor metabolizer compared with the rest of the participants. Later analysis found that this poor metabolizer carried the G143E polymorphism in CES1 and the D260fs polymorphism in CES1P1 (Zhu et al., 2008). This study also concluded that though CES1 metabolism is substantially stereoselective toward $l$-methylphenidate, $d$-methylphenidate metabolism is also significantly impacted by CES1 dysfunction.

Following the discovery of the G143E variant, a retrospective study was conducted to examine the methylphenidate response in Hungarian patients with ADHD; G143E $(n=7)$ carriers and noncarriers $(n=115)$ were compared. Even though the CES1 genotype could not explain the entire interindividual variability between responders $(n=90)$ and nonresponders $(n=32)$, the study demonstrated an association between G143E polymorphism and methylphenidate dose reduction: five responders who had the G143E polymorphism required lower doses of methylphenidate for symptom reduction $(0.410 \mathrm{vs} .0 .572 \mathrm{mg} / \mathrm{kg}, P=$ 0.022) (Nemoda et al., 2009). In 2017, a healthy volunteer study confirmed the significance of G143E in the PK of methylphenidate. In this open-label, prospective clinical trial $(n=22)$, study participants carrying the G143E SNP $(n=6)$ had approximately $152.4 \%$ higher median AUC of $d$-methylphenidate $\left(53.3 \mathrm{ng} \times \mathrm{ml}^{-1} \times \mathrm{h}^{-1}\right)$ than the noncarrier group $\left(21.4 \mathrm{ng} \times \mathrm{ml}^{-1} \times \mathrm{h}^{-1}\right)(P<0.0001)($ Stage et al., 2017a).

The above studies suggest that G143E carriers may be at high risk of being exposed to a toxic methylphenidate concentration. This result is clinically impactful because methylphenidate is considered as the first-line pharmacotherapy for ADHD, with approximately 40 million prescriptions dispensed every year (Schubert et al., 2010). This result could potentially explain why many patients have an unsatisfactory response to the treatment. Further clinical studies in patients with ADHD with larger sample sizes are needed to fully understand the effect of CES1 variants on the efficacy and toxicity of methylphenidate, and how methylphenidate doses should be adjusted based on a patient's CES1 genotypes.

G143E and Clopidogrel (Plavix). Clopidogrel is a P2Y12 inhibitor and has several clinical indications, including myocardial infarction prophylaxis, cerebrovascular accident prophylaxis, and peripheral arterial occlusive disease prophylaxis. Clopidogrel is usually considered as the first-line antiplatelet agent because of its proven efficacy and costeffectiveness (Wiviott et al., 2007; Wallentin et al., 2009; Roe et al., 2012). Clopidogrel is a non-ester-prodrug that needs to be activated by two oxidation reactions via several CYPs (Fig. 3). CYP2C19 pharmacogenetics and its impact on clopidogrel activation have been extensively studied. The Clinical Pharmacogenetics Implementation Consortium guidelines and the FDA both recommend intermediate and poor metabolizers of CYP2C19 to use an alternative antiplatelet agent, such as ticagrelor or prasugrel (Scott et al., 2013). Clopidogrel and its intermediate and active metabolites are all CES1 substrates and metabolized by CES1 to inactive hydrolytic metabolites (Fig. 3). Approximately $85 \%$ of clopidogrel is hydrolyzed by CES1, and only $15 \%$ clopidogrel enters the CYPs-mediated activation pathway (Zhu et al., 2013). Thus, patients with CES1 dysfunction would have a higher concentration of clopidogrel active metabolite compared with normal CES1 metabolizers when taking the same dose. However, the impact of CES1 on the PK and PD of clopidogrel is less studied than the impacts of CYPs.

Two clinical trials support that CES1 G143E carriers have significantly higher plasma concentrations of clopidogrel active metabolite compared with noncarriers. A retrospective subanalysis was performed on participants of the Pharmacogenomics of Antiplatelet Intervention (PAPI) Study $(n=506)$ and on patients who were treated with clopidogrel at Sinai Hospital $(n=350)$ to examine the effect of CES1 G143E on clopidogrel metabolism. Study participants received a 300-mg loading dose of clopidogrel followed by a 75-mg maintenance dose for 6 days, and platelet aggregation was measured as a PD marker. A $50 \%$ higher active metabolite concentration was observed in $\mathrm{G} 143 \mathrm{E}$ 

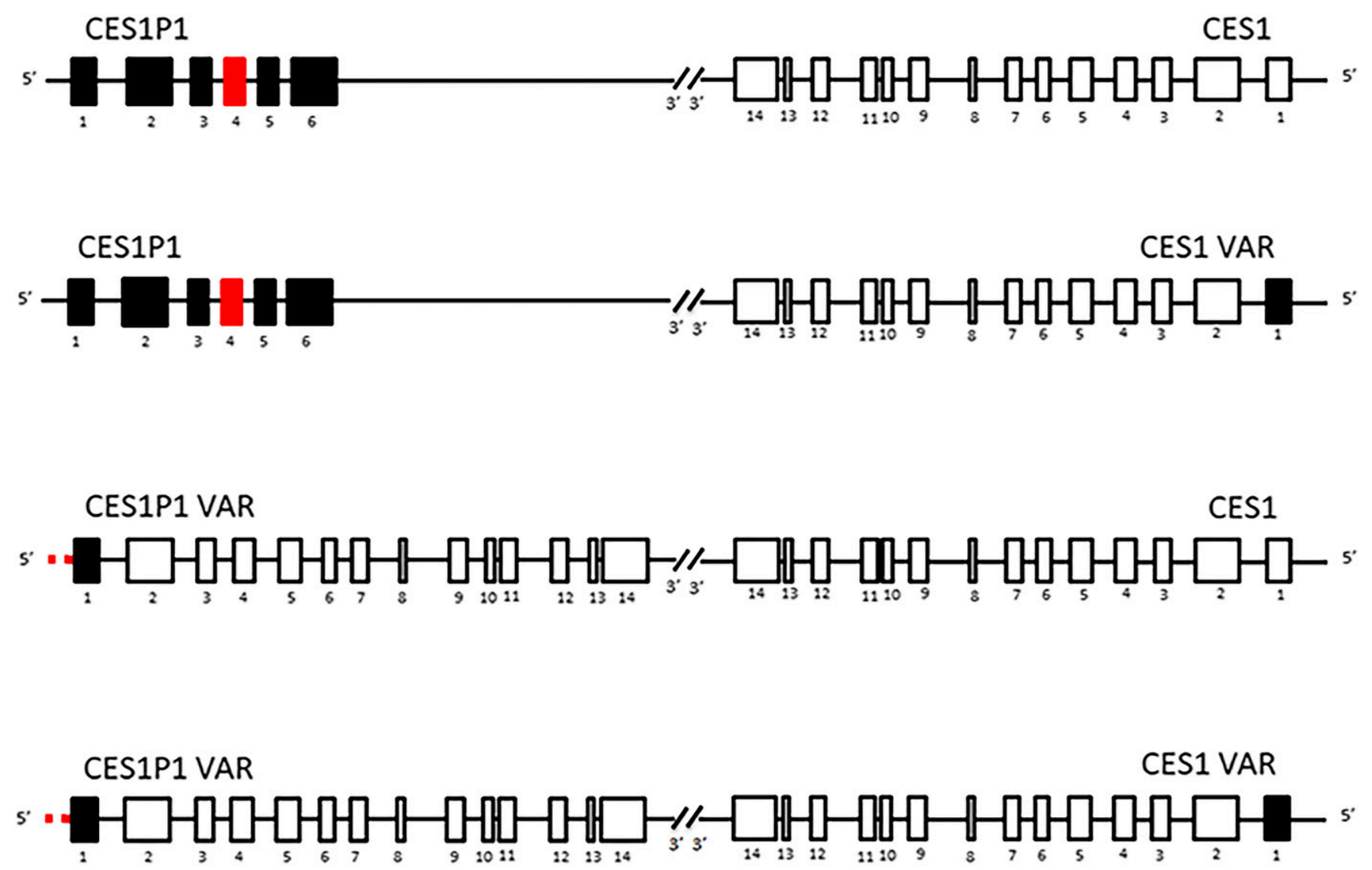

Fig. 1. CES1 gene structure and haplotypes. CES1 gene consists of 14 exons located on chromosome 16q13-q22.1, and CES1P1 is a pseudogene, lying tail-to-tail with CES1. CES1, CES1P1, and their variants CES1 VAR and CES1P1 VAR form four major haplotypes. Red represents where stop codon is located. Transcription efficiency of CESIPI VAR is approximately $2 \%$ of CES1.

carriers $(n=7,30.3 \mathrm{ng} / \mathrm{ml})$ compared with noncarriers $(n=499,19.0 \mathrm{ng} /$ ml) $(P=0.001)$. In addition, the inhibition of adenosine diphosphate (ADP)-induced platelet aggregation was $24 \%$ higher in G143E carriers (reduced to $71 \%$ from baseline) relative to noncarriers (reduced to 57\% from baseline) $(P=0.003)$ (Lewis et al., 2013; Bozzi et al., 2016; Jiang et al., 2016). Another prospective, single-dose, healthy volunteer $(n=22)$ clinical study was conducted by Tarkiainen et al. (2015a) to determine the effect of CES1 G143E on clopidogrel metabolism. The authors found that the $\mathrm{AUC}_{0-\infty}$ ratio of clopidogrel carboxylic acid [inactive metabolite (1) in Fig. 3] to clopidogrel was 53\% less in G143E carriers $(n=10)$ than noncarriers $(n=12)(P=0.009)$. The G143E carriers also exhibited significantly higher plasma concentrations of the parent compound clopidogrel $(P=0.004)$ and its active metabolite $(P=0.009)$ compared with noncarriers. In agreement with the PK

TABLE 2

In vitro kinetics of wild-type CES1 in human liver S9 fractions (HLS9)

\begin{tabular}{|c|c|c|c|c|}
\hline \multirow[b]{2}{*}{ CES1 Substrates } & \multicolumn{3}{|c|}{ HLS9 } & \multirow[b]{2}{*}{ Reference } \\
\hline & Vmax (pmol/min per milligram protein) & $\begin{array}{c}\mathrm{Km} \\
(\mu \mathrm{M})\end{array}$ & $\begin{array}{l}\text { Catalytic Efficiency }(V \max / \mathrm{Km}, \mu \mathrm{l} / \mathrm{min} \text { per } \\
\text { milligram protein) }\end{array}$ & \\
\hline Clopidogrel & 3558.6 & 62.7 & 56.8 & Zhu et al., 2013 \\
\hline 2-oxoclopidogrel (clopidogrel intermediate) & 158.1 & 2.4 & 65.9 & \\
\hline Enalapril & 67.5 & 60.1 & 1.1 & Wang et al., 2016b \\
\hline Ramipril & 18,100 & 690.4 & 26.2 & \\
\hline Perindopril & 18,100 & 1767 & 23.3 & \\
\hline Moexipril & 4400 & 1457 & 12.7 & \\
\hline Fosinopril & 1400 & 471.3 & 3.0 & \\
\hline l-methylphenidate & 1701 & 775.7 & 2.2 & Zhu et al., 2008 \\
\hline$d$-methylphenidate & 177.2 & 663.5 & 0.3 & \\
\hline Oseltamivir & 145,000 & 1380 & 105.1 & Zhu and Markowitz, 2009 \\
\hline Trandolapril & 103,600 & 639.9 & 161.9 & Zhu et al., 2009b \\
\hline Dabigatran & 1174 & 33.5 & 35.0 & Laizure et al., 2014 \\
\hline
\end{tabular}




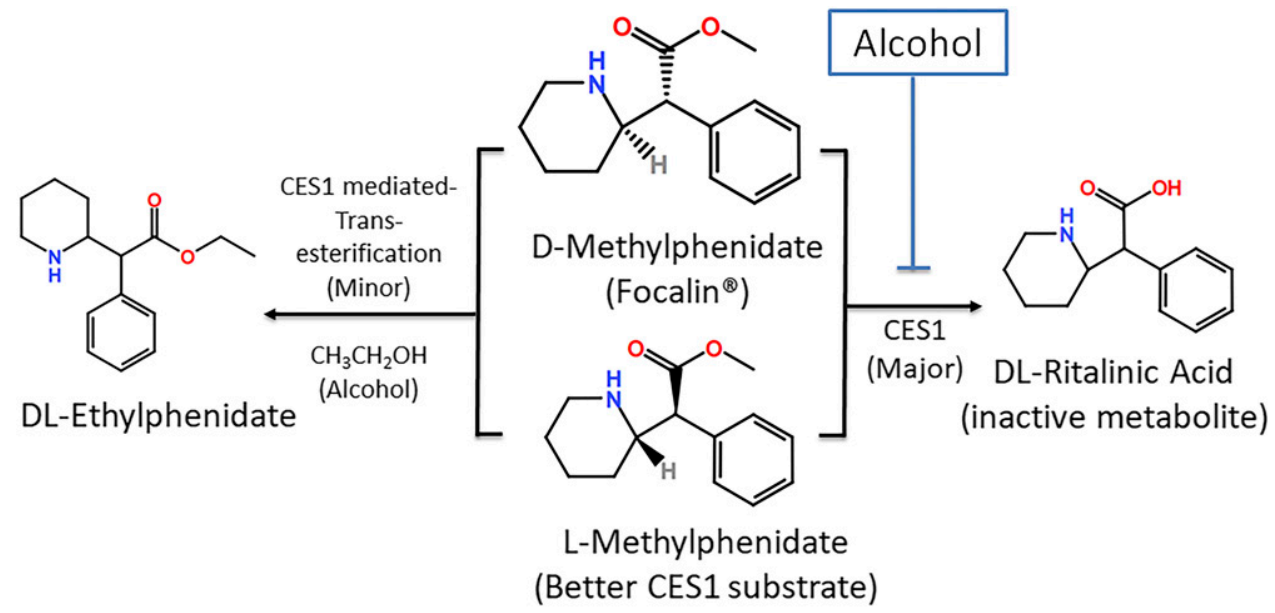

Fig. 2. $D$-methylphenidate comes as a single active ingredient (Focalin) or in combination with $l$-methylphenidate (racemic mixture) (Ritalin). $D$-methylphenidate is approximately 10 times more pharmacologically potent than $l$-methylphenidate, whereas $l$-methylphenidate is a better CES1 substrate. Ethylphenidate can be formed via transesterification with ethanol.

findings, the average inhibition of P2Y12-mediated platelet aggregation in the carriers was $19 \%$ points higher than in noncarriers $(P=0.036)$ (Zhu et al., 2013; Tarkiainen et al., 2015a). The findings of the above two studies are especially important for patients on triple antithrombotic therapy with a high bleeding risk (Mehta et al., 2001; Steinhubl et al., 2002; Shmyr et al., 2017). Clopidogrel dose adjustment may be necessary to prevent potential toxicity (i.e., bleeding) in patients with CES1 dysfunction.

G143E and Angiotensin-Converting Enzyme Inhibitors. Angiotensin-converting enzyme inhibitors (ACEIs) are generally considered to be the first-line therapy for heart failure and hypertension, and approximately 150 million ACEI prescriptions are filled in the United States annually (Mahmoudpour et al., 2015). Currently, 8 out of 10 FDAapproved ACEIs are ester-containing prodrugs, and all ACEI prodrugs<smiles>COC(=O)[C@@H](c1ccccc1Cl)N1CCc2sccc2C1</smiles>

Clopidogrel (Prodrug)

Inactive Metabolite (1) CYPS<smiles>COC(=O)[C@H](c1ccccc1Cl)N1CCC2SC(=O)C=C2C1</smiles>
CES1 Intermediate Metabolite Inactive Metabolite (2)<smiles>COC(=O)[C@H](c1ccccc1Cl)N1CC[C@@H](O)/C(=C/C(=O)O)C1</smiles><smiles>O=C(O)/C=C1\CN([C@H](C(=O)O)c2ccccc2Cl)CC[C@H]1O</smiles>

\section{Active Metabolite}

Inactive Metabolite (3)

Fig. 3. Clopidogrel metabolic pathway. Clopidogrel is a non-ester-prodrug that needs to be activated by two oxidation reactions via CYPs. Clopidogrel and its intermediate and active metabolites are all metabolized (deactivated) by CES1. need to be activated by CES1 to exert their intended therapeutic effects (Chaturvedi, 2004; Yancy et al., 2017). The activation is essential for the pharmacological effects because the active metabolites are 10-1000 times more potent than their prodrug forms (Foye et al., 2013). Therefore, patients with CES1 dysfunction would have a lower concentration of the ACEI active metabolite relative to normal CES1 metabolizers (Fig. 4).

A prospective, single-dose pharmacokinetic clinical study was conducted in healthy volunteers to examine the effect of the G143E variant on the activation of the ACEI prodrugs enalapril and quinapril. The $\mathrm{AUC}_{0-\infty}$ of the enalapril active metabolite enalaprilat was found to be $20 \%$ lower in the G143E carriers $(n=10)$ than in noncarriers $(n=12)$ $(P=0.049)$ (Tarkiainen et al., 2015b). This finding is consistent with an in vitro study that showed that enalapril activation was impaired in liver samples carrying the G143E variant (Wang et al., 2016b). However, the $\mathrm{AUCs}_{0-\infty}$ of the quinapril and its active metabolite (quinaprilat) were not significantly different between carriers and noncarriers $(P=0.114)$. Further investigations are warranted to fully understand the effect of CES1 variants on the PK and PD of ACEI prodrugs.

G143E and Oseltamivir (Tamiflu). Oseltamivir is an antiviral drug that has an FDA indication for influenza types A and B infections. Even though oseltamivir is rarely effective because of its specific administration requirement (i.e., this medication should be taken within 2 days of

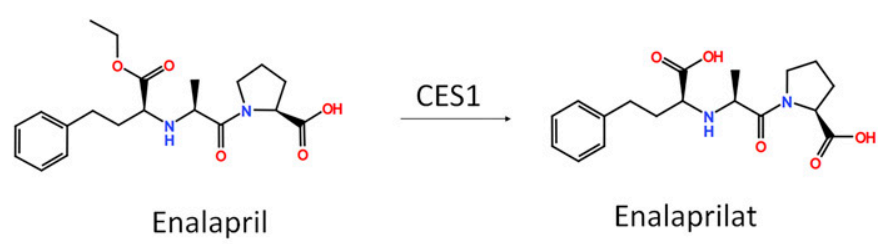<smiles>CCOC(=O)[C@H](CCc1ccccc1)N[C@@H](C)C(=O)N1[C@H](C(=O)O)C[C@H]2CCCC[C@H]21</smiles><smiles>C[C@H](N[C@@H](CCc1ccccc1)C(=O)O)C(=O)N1[C@H](C(=O)O)C[C@@H]2CCCC[C@]21C</smiles>

Trandolapril

Fig. 4. ACE inhibitors (enalapril and trandolapril) metabolism. Enalapril and trandolapril are ester-prodrugs that need to be activated by CES1. 
onset of symptoms to reduce flu duration by approximately 1 day), oseltamivir remains one of the most prescribed drug products because of flu epidemics (Singh et al., 2003; Dahlgren et al., 2018). As an esterprodrug, oseltamivir needs to be activated by CES1 into its active metabolite, oseltamivir carboxylate (Shi et al., 2006). An in vitro study based on cell lines stably transfected with CES1 variants suggested the G143E SNP markedly impaired CES1 activity in oseltamivir activation (Zhu and Markowitz, 2009).

To examine the effect of G143E on oseltamivir PK and activation, a prospective, single-dose pharmacokinetic clinical study was conducted in healthy volunteers consisting of nine G143E heterozygotes, one G143E homozygote, and 12 noncarriers. The $\mathrm{AUC}_{0-\infty}$ ratio of oseltamivir carboxylate (active metabolite) to oseltamivir (parent molecule) was $23 \%$ lower in G143E heterozygotes compared with noncarriers $(P=0.006)$. The one $\mathrm{G} 143 \mathrm{E}$ homozygous individual had an $\mathrm{AUC}_{0-\infty}$ of oseltamivir that was approximately $360 \%$ greater than that of the noncarriers, indicating that loss of CES1 activity could profoundly impair oseltamivir activation (Tarkiainen et al., 2012).

G143E and Dabigatran and Sacubitril. Dabigatran and sacubitril are both prodrugs that need to be activated by CES1 in the liver (Fig. 5). In vitro studies showed that the formation rates of the active metabolites of dabigatran and sacubitril were significantly lower in human livers carrying the G143E variant than in noncarrier samples (Shi et al., 2016b,c). However, it remains undetermined whether the variant can affect the activation and therapeutic response of these two drugs in patients.

\section{Pharmacogenetics of Other CES1 Genetic Variants}

In addition to G143E, many other CES1 variants have been studied for their effects on the PK and PD of CES1 substrate drugs. However, the results were generally inconclusive, and further studies are needed to determine the clinical significance of these variants.

E220G (rs200707504). A nonsynonymous variant E220G, commonly referred to as c.662A $>\mathrm{G}$, was suggested to decrease CES1 enzymatic activity in an in silico analysis (Oh et al., 2017). In agreement with that prediction, an in vitro study on transfected cell lines found E220G markedly decreased CES1 activity and the metabolisms of several CES1 substrates, including enalapril, clopidogrel, and sacubitril (Wang et al., 2017). Notably, E220G has a MAF of $0.55 \%$ in East Asians but is rare in other populations. To determine the clinical impact of E220G on the PK of a CES1 substrate, a single-dose oseltamivir (75 mg) PK study was conducted in 20 healthy Korean volunteers. In this study, the variant was observed to have a marginal effect on the PK of oseltamivir and its active metabolite (oseltamivir carboxylate); however, the differences were statistically insignificant. In the E220G carriers $(n=8)$, the $\mathrm{AUC}_{0-48} \mathrm{~h}$ of oseltamivir was increased by $10 \%(P=$ $0.334)$, and the $\mathrm{AUC}_{0-48} \mathrm{~h}$ of oseltamivir carboxylate was decreased by $5 \%(P=0.513)$ relative to the noncarriers $(n=12)(\mathrm{Oh}$ et al., 2017).

S75N (rs2307240). S75N is one of the most common CES1 nonsynonymous SNPs, with MAFs ranging from $2 \%$ to $7 \%$ in different populations. A retrospective pharmacodynamics analysis was conducted to examine the effect of CES1 S75N on the outcome of clopidogrel therapy in patients with the coronary syndrome $(n=851)$. The result showed that CES1 S75N carriers $(n=372)$ had higher incidence of cerebrovascular events $(P<0.001)$, acute myocardial infarction $(P<0.001)$, and unstable angina $(P<0.001)$ compared with noncarriers. The study also found that the $\mathrm{S} 75 \mathrm{~N}$ polymorphism was more frequent in patients with acute coronary syndrome (MAF 22\%) than in the general population (MAF 5\%). The authors concluded that there was a significant association between the S75N polymorphism and the outcome of clopidogrel therapy (Xiao et al., 2017). However, this result conflicts with another study that found the $\mathrm{S} 75 \mathrm{~N}$ variant to be not associated with the outcomes of patients treated with methylphenidate (Johnson et al., 2013).

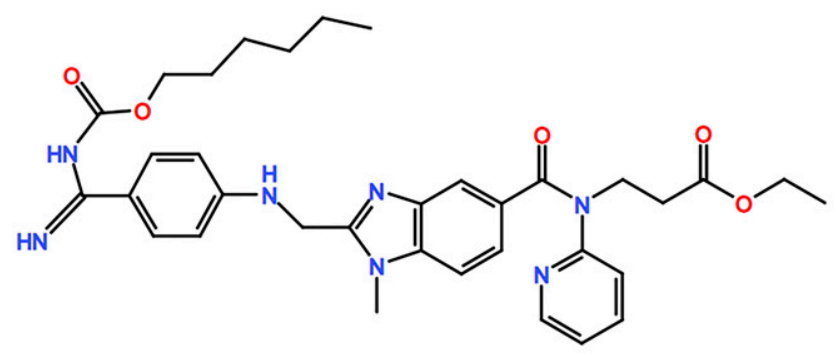

Dabigatran Etexilate
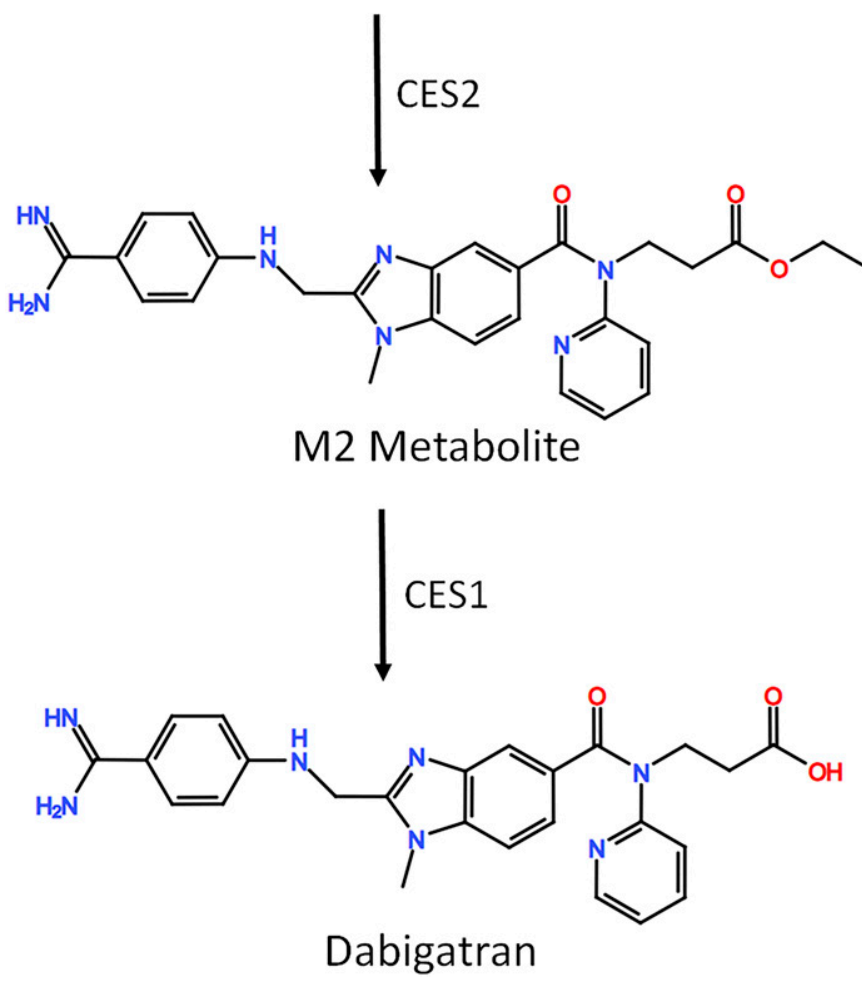

Fig. 5. Dabigatran metabolic pathway. Dabigatran is a prodrug that activated by both CES1 and CES2.

Furthermore, an in vitro study showed the S75N variant did not significantly alter the expression and activity of CES1 in transfected cells and human livers (Wang et al., 2017).

-816A $>$ C (rs3785161). The $-816 \mathrm{~A}>\mathrm{C}$ polymorphism is located in the promoter region of CESIP1 VAR and has been suggested as a potential upregulator of CESIPI VAR expression (Yoshimura et al., 2008). A prospective clinical study was conducted to examine the impact of $-816 \mathrm{~A}>\mathrm{C}$ on the outcome of the ACEI prodrug (imidapril) therapy in patients with hypertension $(n=105)$. The study found that after 8 weeks of imidapril therapy, $-816 \mathrm{~A}>\mathrm{C}$ homozygotes and heterozygotes $(n=47)$ had greater systolic blood pressure reduction $(24.1 \mathrm{~mm}$ $\mathrm{Hg})$ compared with noncarriers $(17.6 \mathrm{~mm} \mathrm{Hg})(P=0.0184)$, indicating increased CES1 functionality in the carriers. The follow-up in vitro study claimed that the $-816 \mathrm{~A}>\mathrm{C}$ SNP may have enhanced transcription of the CES1P1 VAR gene (Geshi et al., 2005). The -816A $>$ C SNP was also evaluated for its impact on the outcomes of dual antiplatelet therapy (i.e., aspirin and clopidogrel) in patients with coronary heart diseases $(n=162)$. The $-816 \mathrm{~A}>\mathrm{C}$ carriers $(n=75)$ had decreased vasodilator-stimulated phosphoprotein-platelet reactivity index (VASPPRI) $(P=0.014)$, indicating increased CES1 function in the carriers (Xie et al., 2014). 
However, conflicting findings were reported by other studies. In a study involving the outcome of clopidogrel treatment in patients undergoing percutaneous coronary intervention, -816A $>\mathrm{C}$ carriers showed a lower ADP-induced maximum platelet aggregation $(21.5 \%, n=125)$ compared with noncarriers $(31.7 \%, n=124)$ $(P=0.001)$, indicating decreased CES1 function (Zou et al., 2014). Zhu et al. (2014) also performed a retrospective pharmacogenetic analysis of the INternational VErapamil SR Trandolapril study $(n=486)$ and did not find an association between $-816 \mathrm{~A}>\mathrm{C}$ and the blood pressure-lowering effect of trandolapril. The follow-up in vitro study also showed $-816 \mathrm{~A}>\mathrm{C}$ genotype was not significantly associated with CES1 protein expression and trandolapril activation in human liver samples ( $n=100)$ (Zhu et al., 2016). Other researchers also noted that the CES1P1 VAR gene, which contains $-816 \mathrm{~A}>\mathrm{C}$, is considered functionally insignificant because of its low transcription efficiency (Tanimoto et al., 2007; Hosokawa et al., 2008).

-75G $>$ T (rs3815583). The -75G $>$ T SNP is located in the promoter region of CES1 and was suspected to alter CES1 expression in the liver; however, the findings are conflicted. A study was performed to determine the association between the variant and appetite reduction (a side effect of methylphenidate) in children with $\operatorname{ADHD}(n=213)$. Appetite reduction was measured by the Barkley Stimulant Side Effect Rating Scale, and methylphenidate dose was titrated up for 3 months as tolerable. The carrier group $(n=129)$ had worse appetite reduction compared with noncarriers $(n=76)(41 \%$ vs. $77 \%, P=0.01)$, indicating that the variant was associated with decreased CES1 function (Bruxel et al., 2013). A study in patients treated with irinotecan, however, showed a contrary finding, suggesting that the $-75 \mathrm{G}>\mathrm{T}$ variant confers greater CES1 function (Sai et al., 2010). CES1 is involved in the conversion of the prodrug irinotecan to its active metabolite, $\mathrm{SN}-38$, and then is further metabolized by UGT1As to inactive SN-38G. Following irinotecan treatment, patients who carried the $\mathrm{T}$ allele of this variant had higher plasma (SN-38 $+\mathrm{SN}-38 \mathrm{G})$ /irinotecan AUC ratios relative to noncarriers $(P=0.027)$ following irinotecan treatment (Sai et al., 2010).

Other CES1 substrates, isoniazid, and ACEI prodrugs were also studied in the context of $-75 \mathrm{G}>\mathrm{T}$; however, no significant relationships were found between the variant and the medication responses. In one such study, the variant was evaluated for its effect on the outcomes of ACEI prodrugs in patients with congestive heart failure $(n=200)$ who underwent ACEI prodrug dose titrations. The study reported $-75 \mathrm{G}>\mathrm{T}$ did not significantly impact plasma angiotensin (AT) II/ATI ratios, and furthermore, the $-75 \mathrm{G}>\mathrm{T}$ variant was not significantly associated with fatal outcomes (i.e., cardiovascular death and all-cause death) (Nelveg-Kristensen et al., 2016). The study with isoniazid had similar results showing no significant association between the variant and isoniazid-induced hepatotoxicity $(n=170)$ (Yamada et al., 2010).

1168-33C $>$ A (rs2244613). Dabigatran (Pradaxa) is a prodrug that needs to be activated by both CES1 and CES2 to exert its anticoagulant effect (Fig. 5). Paré and associates (2013) conducted a genome-wide association study of dabigatran in participants $(n=2944)$ of the Randomized Evaluation of Long-term Anticoagulation Therapy clinical trial. The researchers concluded the CES1 intronic variant 1168-33C $>\mathrm{A}$ (rs2244613) is associated with lower trough concentrations of the active metabolite $[15 \%$ decrease per allele; $95 \%$ confidence interval (CI) $10 \%-19 \%$ ] and a lower risk of any bleeding (odds ratio, 0.67; 95\% CI 0.55-0.82) compared with noncarriers (Paré et al., 2013). However, an in vitro study did not find the variant to be associated with CES1 protein expression and dabigatran metabolism in human livers (Shi et al., $2016 \mathrm{~b}$ ). A prospective study also examined the impact of $1168-33 \mathrm{C}>\mathrm{A}$ in patients with ADHD that were treated with methylphenidate. The study found the variant to be associated with the occurrence of sadness, a side effect of short-acting methylphenidate. However, researchers concluded this might be due to linkage disequilibrium with two SNPs of the noradrenaline transporter gene (Johnson et al., 2013).

Copy Number Variation (i.e., CES1P1/CES1P1 VAR). Many researchers have studied the impact of copy number variations (CNVs) on CES1 functionality; however, the results are conflicted. Stage et al. (2017a) found that participants with four functional copies of CES1 $(n=5)$ had an increased AUC of $d$-methylphenidate relative to the control group with two functional copies of CES1 $(n=17)(61 \%$ increase, $P=0.011)$; participants with three copies of CES1 $(n=2)$ had $45 \%$ increased AUC compared with the control group $(P=0.028)$. Stage et al. (2017b) conducted a similar study with enalapril $(n=43)$; however, they could not find a statistically significant correlation between $\mathrm{CNV}$ and enalapril PK. When Sai et al. (2010) examined the effect of CNV on the irinotecan exposure, they found patients with multiple CES1 copies (i.e., three or four) to have 1.24-fold higher irinotecan AUC relative to patients with two copies of CES1 $(P=0.0134)$. Many researchers, however, did not find the relationship between CNVs and CES1 function. Suzaki et al. (2013b) evaluated the relationship between CNVs of CES1 and oseltamivir PK parameters but did not find any correlation. Nelveg-Kristensen et al. (2016) studied the relationship between $\mathrm{CNV}$ and ACEI prodrugs, and again, no association was found. Moreover, an in vitro study showed CES1 protein expression levels to be comparable among human livers with different copy numbers of functional CESI gene (Wang et al., 2016b).

Other CES1 SNPs. In addition to the polymorphisms discussed above, sporadic reports have stated several CES1 SNPs to be associated with the outcomes of CES1 substrate medications. For example, the SNP $1315+2025 \mathrm{~A}>\mathrm{C}(\mathrm{rs} 8192950)$ was associated with a decreased risk of ischemic events in patients $(n=64)$ having symptomatic extracranial or intracranial stenosis and receiving dual antiplatelet therapy with clopidogrel for a minimum of 5 days (Zhao et al., 2016). Another retrospective subanalysis of a capecitabine clinical study identified associations of 1168-41C $>\mathrm{T}$ (rs2244614), $690+129 \mathrm{del}$ (rs3217164), 95346T $>\mathrm{C}(\mathrm{rs} 7187684),-1232 \mathrm{~A}>\mathrm{G}(\mathrm{rs} 1186118)$ with severe early onset of capecitabine-induced toxicity (Hamzic et al., 2017). None of these findings have been validated independently.

A rare LOF variant, D260fs (c.70DelT), was reported in a clinical study (Zhu et al., 2008). D260fs causes a deletion in exon 6, resulting in a frameshift and premature truncation. Moreover, an in vitro study with CES1 variant-transfected cell lines examined the SNPs proximate to the CES1 active site and identified four LOF nonsynonymous SNPs: G142E, G147C, Y170D, and R171C. However, these variants appear to be clinically insignificant because of their low MAFs $(<0.4 \%)$ (Wang et al., 2017).

The above-mentioned CES1 SNPs and their impacts on the PK and PD of CES1 substrate medications are summarized in Table 3.

\section{Nongenetic Factors Affecting CES1 Expression and Activity Developmental Expression of CES1}

The developmental expression patterns of CES1 in human and mouse livers were similar, and many in vitro studies have suggested that hepatic CES1 protein expression increases with age (Zhu et al., 2009a; Hines et al., 2016; Boberg et al., 2017). An in vitro study with human liver samples $(n=104)$ demonstrated the adult group ( $\geq 18$ years of age) to have had higher CES1 expression than children (0 days-10 years); meanwhile, child group had higher CES1 expression than fetuses (82-224 gestation days). A follow-up study with liver microsomes showed that, in parallel with expression level, CES1 activity on hydrolyzing its substrate oseltamivir was also positively correlated with age (Yang et al., 2009). The same group did a similar in vitro human liver study with a slightly different age bracket, in which the 


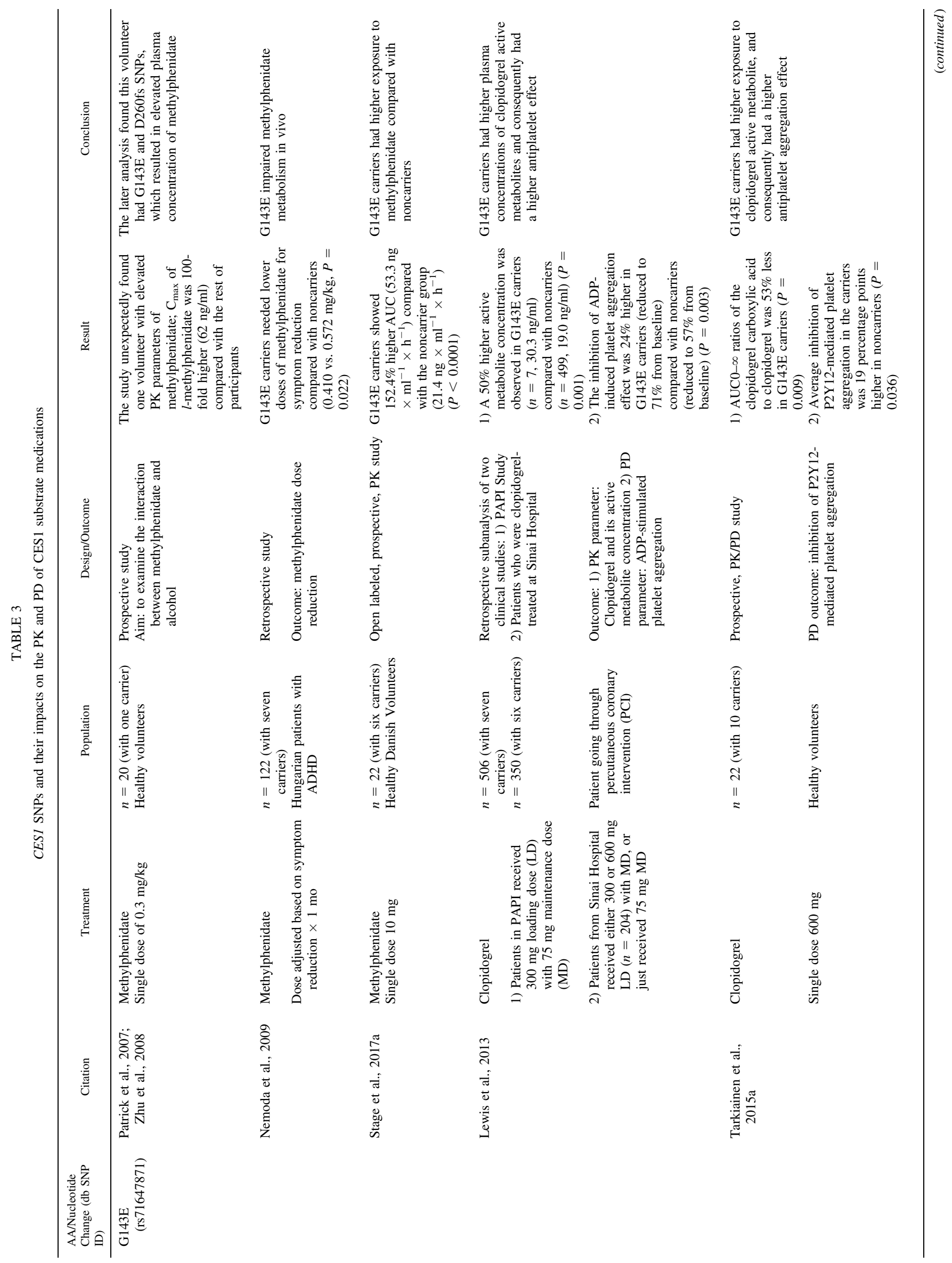

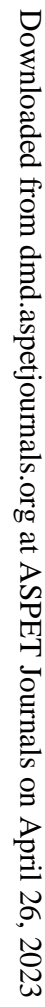




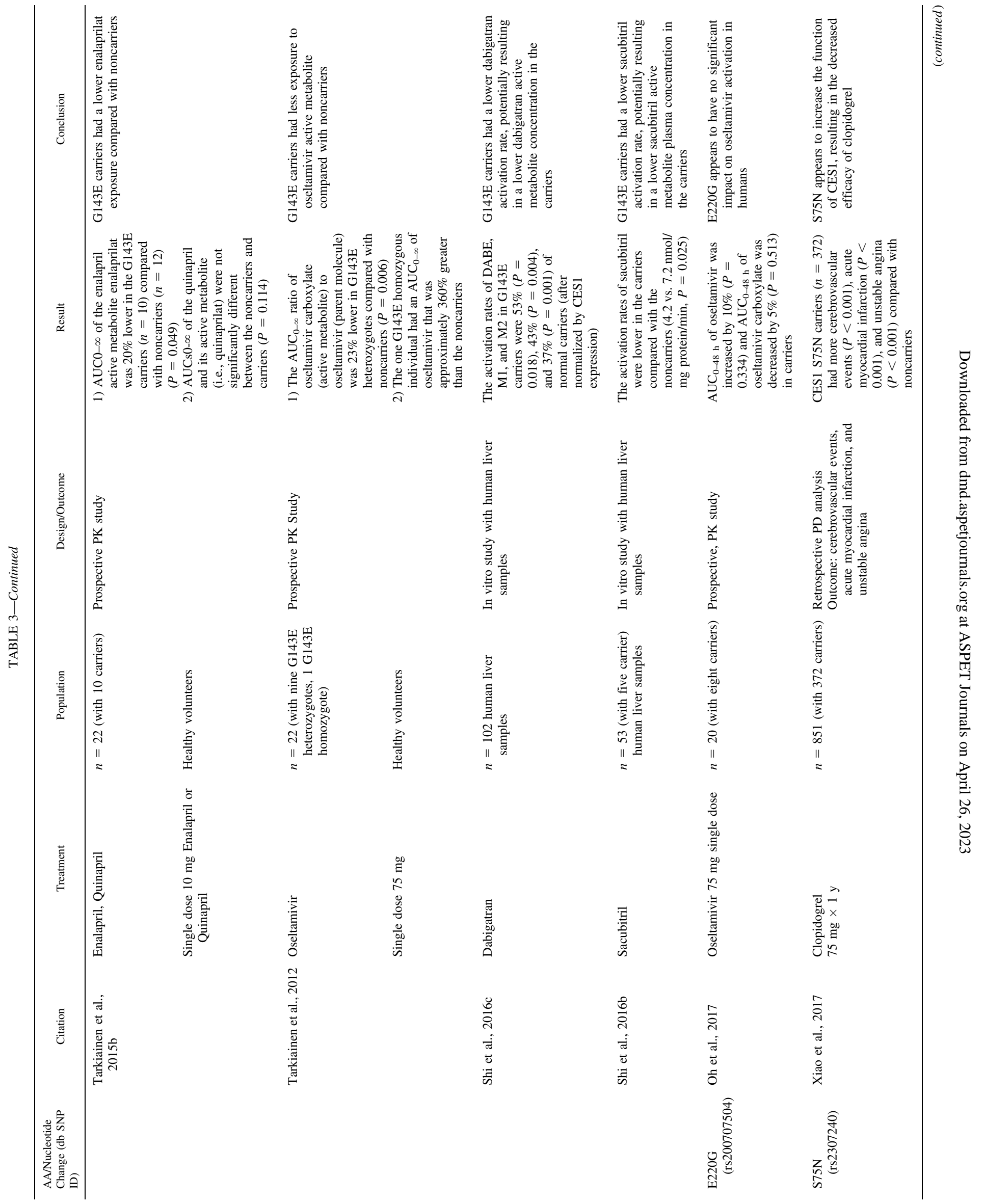




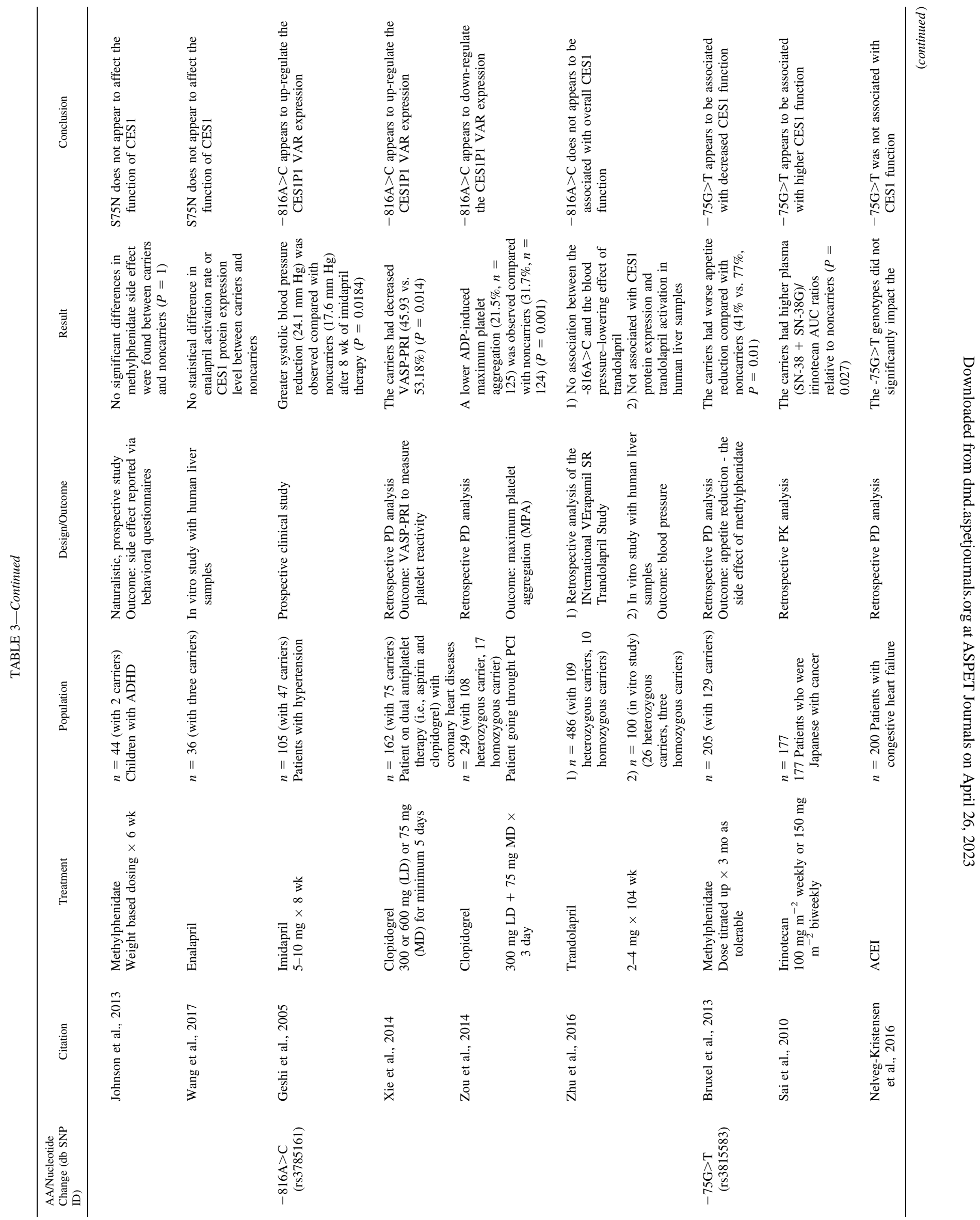


liver samples were divided into five age groups: 1-31 days old (group 1), 35-70 days old (group 2), 89-119 days old (group 3), 123-198 days old (group 4), and over 18 years old (group 5). Neonates (group 1) had $10 \%$ of the CES1 expression and hydrolysis levels compared with the adult group (group 5); pediatric groups (Group 2-4) had approximately $50 \%$ of the CES1 expression and hydrolysis levels compared with an adult (Shi et al., 2011). Lastly, a similar in vitro study quantified CES1 protein levels in human liver samples of various ages $(n=165)$. CES1 expression levels were $4.76 \mathrm{pmol} / \mathrm{mg}$ from birth to 3 weeks $(n=36) ; 15.8$ $\mathrm{pmol} / \mathrm{mg}$ for those aged 3 weeks to 6 years $(n=90)$; and $16.6 \mathrm{pmol} / \mathrm{mg}$ for ages $6-18$ years $(n=36)$. The study team concluded that the median CES1 expression level is directly correlated with age $(P<0.001)$ (Hines et al., 2016). Overall, CES1 expression and activity levels are lower in neonates and pediatric cohorts; further studies are warranted to investigate the potential effect of CES1 maturation on the treatment outcome of CES1 substrate medications in patients in the early stages of development.

\section{Sex Difference of CES1 Expression}

Both in vitro and clinical studies have suggested that CES1 expression is higher in females than in males (Patrick et al., 2007; Zhu et al., 2009a; Shi et al., 2016b). A PK study on healthy volunteers revealed that males had significantly higher exposure to d-methylphenidate than females (Patrick et al., 2007). Nonetheless, females experienced a more pronounced stimulant effect despite their lower exposure. Shi et al. (2016b) observed significantly higher CES1 activity in female human liver samples $(n=56)$ compared with male samples $(n=46)$. A follow-up in vitro study with dabigatran suggested CES1 activity was higher in females than males (Shi et al., 2016b). However, such difference was not observed in another in vitro study using human liver samples $(n=32)$ and mouse liver samples $(n=9)$ (Zhu et al., 2009a). Further study is needed to examine the impact of sex on the CES1 expression level and the PK and PD of CES1 substrates.

\section{Drug-Drug Interactions}

CES1 Inhibitor-Alcohol. To date, ethanol is the only known CES1 inhibitor that has been confirmed in multiple in vivo and in vitro studies. The impact of ethanol on the metabolism of the CES1 substrate, methylphenidate, was tested in healthy volunteers $(n=14)$ (Zhu et al., 2017). $D$-methylphenidate comes as a single active ingredient (Focalin) or in combination with $l$-methylphenidate (racemic mixture, Ritalin). $D$-methylphenidate is approximately 10 times more pharmacologically potent than $l$-methylphenidate, whereas $l$-methylphenidate is a more efficient CES1 substrate (Fig. 2). This clinical study used a pulsatile dosing regimen with methylphenidate ( $d l$-methylphenidate $40 \mathrm{mg}$ or $d$-methylphenidate $20 \mathrm{mg})$ and ethanol $(0.6 \mathrm{~g} / \mathrm{kg}$, 4 hours after methylphenidate dose) to eliminate any potential confounding effect of ethanol on methylphenidate absorption because the methylphenidate drug products (i.e., Ritalin and Focalin) might undergo faster gastric dissolution in the stomach if administered with alcohol. When alcohol and d-methylphenidate (Focalin) were coadministered, the $\mathrm{C}_{\max }$ of $d$-methylphenidate was elevated by $27 \%(P=0.001)$, and the $\mathrm{AUC}_{4 \rightarrow 8 \mathrm{~h}}$ was elevated by $20 \%(P<0.01)$; when alcohol and $d l$-methylphenidate (Ritalin) were coadministered, the $\mathrm{C}_{\max }$ of $d$-methylphenidate was elevated by $35 \%(P<0.01)$, and the $\mathrm{AUC}_{4 \rightarrow 8 \mathrm{~h}}$ was elevated by $25 \%(P<0.05)$ (Zhu et al., 2017). These results are consistent with the previous clinical trial by Patrick et al. (2013). In that study, when alcohol and $d$-methylphenidate (Focalin) were coadministered, the $d$-methylphenidate AUC was increased by $14 \%$; when alcohol and $d l$-methylphenidate (Ritalin) were coadministered, the $d$-methylphenidate AUC was increased by $21 \%$ (Patrick et al., 2013). Patrick and colleagues (2007) also showed 
TABLE 4

Drug-drug interaction summary

\begin{tabular}{|c|c|c|}
\hline CES1 Inhibitors & CES1 Substrates & Interaction Summary \\
\hline Alcohol & Methylphenidate & $\begin{array}{l}\text { Many in vitro and in vivo studies confirmed alcohol inhibits CES1 and mediates biotransformation of } \\
\text { methylphenidate to ethylphenidate; methylphenidate plasma concentrations were increased when patients } \\
\text { took methylphenidate with alcohol (Griffin et al., 2010, 2013; Bell et al., 2011a,b; Zhu et al., 2011, 2017; } \\
\text { Patrick et al., 2013; Parker et al., 2015). }\end{array}$ \\
\hline Alcohol & Oseltamivir & $\begin{array}{l}\text { When alcohol was administered with oseltamivir in humans, the AUC of oseltamivir increased by } 37 \% \text { (Hu } \\
\text { et al., 2014). }\end{array}$ \\
\hline Cannabis & Oseltamivir & $\begin{array}{l}\text { In vitro study with CES1-transfected cells suggested THC, CBD, and CBN to be the potent CES1 inhibitors. } \\
\text { The inhibition constant (Ki) values for THC, CBD, and CBN were } 0.541,0.974 \text {, and } 0.263 \mu \mathrm{M}(0.170 \text {, } \\
0.306 \text {, and } 0.0817 \mu \mathrm{g} / \mathrm{ml}) \text { (Qian et al., 2019). }\end{array}$ \\
\hline $\begin{array}{l}\text { Protease } \\
\text { Inhibitors }\end{array}$ & $\begin{array}{l}\text { Methylphenidate. PNPA and } \\
p \text {-nitrophenol (PNP) }\end{array}$ & $\begin{array}{l}\text { In vitro study showed that protease inhibitors (i.e., nelfinavir, amprenavir, atazanavir, ritonavir, and } \\
\text { saquinavir) inhibited the catalytic activity of CES } 1(P<0.01) \text {. Among protease inhibitors, nelfinavir had } \\
\text { a significantly higher inhibitory effect compared with other agents (Rhoades et al., 2012). }\end{array}$ \\
\hline Aripiprazole & Methylphenidate, PNPA & $\begin{array}{l}\text { In vitro study suggested aripiprazole, perphenazine, thioridazine, and fluoxetine to be potent inhibitors of } \\
\text { CES1. Among the medications tested, aripiprazole was the most potent inhibitor of CES1, and an in vivo } \\
\text { study with FVB mouse confirmed this result (Zhu et al., 2010). }\end{array}$ \\
\hline $\begin{array}{l}\text { Isradipine/ } \\
\text { Tacrolimus }\end{array}$ & PNPA, trandolapril & $\begin{array}{l}\text { In vitro study with human liver microsomes suggested isradipine [dihydropyridine calcium antagonist (DHP)] } \\
\text { and tacrolimus (immunosuppressive agent) to be potent CES1 inhibitors (Thomsen et al., 2014). }\end{array}$ \\
\hline Valproate & Rufinamide & $\begin{array}{l}\text { In vitro study suggested valproate could inhibit CES1 function and affect rufinamide metabolism (Williams } \\
\text { et al., 2011). }\end{array}$ \\
\hline ACEI & Clopidogrel & $\begin{array}{l}\text { ACEIs and clopidogrel are often administered together as both of them are cardiovascular medications; both } \\
\text { ACEIs and clopidogrel are suggested to be inhibitors of CES1. A clinical study with patients with } \\
\text { myocardial infarction }(n=70,934) \text { demonstrated concomitant use of ACEIs increased the rate of clinically } \\
\text { significant bleeding compared with the clopidogrel monotherapy }(P=0.002) \text { (Kristensen et al., 2014). } \\
\text { Another clinical study with patients with myocardial infarction }(n=45,918) \text { with clopidogrel showed that } \\
\text { concomitant use of clopidogrel and ACEI (perindopril and ramipril) was not associated with the re- } \\
\text { infarction, heart failure or death (Cressman et al., 2015). }\end{array}$ \\
\hline
\end{tabular}

that the coadministration of alcohol 30 minutes before or 30 minutes after methylphenidate had a similar impact on methylphenidate exposure. Both authors concluded that alcohol is a strong inhibitor of CES1, and the impact of CES1 inhibition is greater for $d l$-methylphenidate (Ritalin) than for d-methylphenidate (Focalin). Additionally, the DDI between methylphenidate and ethanol produced the transesterification metabolites d-ethylphenidate and $l$-ethylphenidate, and the plasma concentrations of $l$-ethylphenidate were much higher than d-ethylphenidate because of $l$-ethylphehidate being a more efficient CES1 substrate (Zhu et al., 2011, 2017). Other in vivo studies with mice demonstrated similar results (Griffin et al., 2010, 2013; Bell et al., 2011b).

The impact of alcohol on the CES1 function was also examined in the context of a different CES1 substrate, oseltamivir. A prospective health volunteer PK study $(n=18)$ examined the interaction between oseltamivir $150 \mathrm{mg}$ (a recommended daily dose for the treatment of influenza) and alcohol. Alcohol increased the oseltamivir $\mathrm{AUC}_{0-6 \mathrm{~h}}$ by $27 \%(P=0.011)$ and decreased the $\mathrm{AUC}_{0-6} \mathrm{~h}$ ratio of the active metabolite oseltamivir carboxylate to the parent compound oseltamivir by $34 \%(P<0.001)$ (Parker et al., 2015). However, coadministration of alcohol did not significantly affect the $\mathrm{AUC}_{0-24 \mathrm{~h}}$ of oseltamivir carboxylate. These results are consistent with in silico analysis of the DDI between alcohol and oseltamivir (Hu et al., 2014).

Other CES1 Inhibitors: Cannabis, Protease Inhibitors, Aripiprazole, Isradipine, Tacrolimus, Valproate. Besides alcohol, many drug products on the market have been suggested to be potent inhibitors of CES1 mainly by in vitro investigations (Table 4). A further clinical study with a validated CES1 substrate is needed to determine the clinical significance of these CES1 inhibitors.

An in vitro study with CES1-transfected cells suggested that cannabis [i.e., tetrahydrocannabinol (THC), cannabidiol (CBD), and cannabinol $(\mathrm{CBN})]$ can act as a potential CES1 inhibitor. The inhibition constant (Ki) values for THC, CBD, and CBN were $0.541,0.974$, and $0.263 \mu \mathrm{M}$ $(0.170,0.306$, and $0.0817 \mu \mathrm{g} / \mathrm{ml}$ ), respectively (Qian et al., 2019). This result could be clinically impactful because the use of cannabis is expected to increase in the next few years (Hasin, 2018).
Several protease inhibitors (i.e., nelfinavir, amprenavir, atazanavir, ritonavir, and saquinavir) were identified as CES1 inhibitors by an in silico analysis and later confirmed by an in vitro incubation study. Among those, nelfinavir had a significantly higher inhibitory effect than the other agents. The relative CES1 activity toward p-nitrophenyl acetate (PNPA) (a CES1 substrate) was 5.2\%, 74.2\%, 51.7\%, 76.9\%, and $67.8 \%$ of the control after incubation with nelfinavir, ritonavir, amprenavir, saquinavir, and atazanavir, respectively (Rhoades et al., 2012).

An in vitro study suggested aripiprazole, perphenazine, thioridazine, and fluoxetine to be potent inhibitors of CES1, and a complementary animal study $(n=10)$ with FVB mice demonstrated that coadministration of aripiprazole and methylphenidate (CES1 substrate) significantly increased the plasma concentrations of $d l$-methylphenidate $(P<0.01)$ (Zhu et al., 2010).

Moreover, a total of 27 cardiovascular, antiplatelet, anticoagulant, and immunosuppressant drugs have been tested for CES1 inhibition using human liver microsomes and recombinant CES1. The results suggested isradipine (a dihydropyridine calcium antagonist) and tacrolimus (an immunosuppressive agent) to be potent CES1 inhibitors. CES1 activity toward PNPA was decreased to $17.6 \%$ with isradipine and $28.4 \%$ with tacrolimus (Thomsen et al., 2014).

An in vitro study suggested valproate could inhibit CES1 function and affect rufinamide metabolism in both microsomes and cytosol. This result could be clinically significant because the two antiepileptic medications are often prescribed together when monotherapy is ineffective (Williams et al., 2011).

A combined ensemble docking and machine learning approach was used to identify potential CES1 inhibitors from 1114 FDA-approved drugs. Among the identified inhibitor candidates, four drugs including diltiazem, benztropine, iloprost, and treprostinil were found to inhibit CES1 activity in vitro with $\mathrm{IC}_{50}$ values ranging from 13.9 to $391.6 \mu \mathrm{M}$ (Briand et al., 2019).

Lastly, an in vitro study suggested that some naturally occurring oxysterols and fatty acids might significantly inhibit CES1 activity with $\mathrm{IC}_{50}$ values within the micromolar range (Crow et al., 2010). These compounds 
could potentially affect CES1-mediated detoxification and drug metabolism in vivo.

CES1 Inducers. Overall, CES1 inducers are understudied relative to its inhibitors. Evidence suggests that various nuclear receptors might be involved in the regulation of CES1 expression (Staudinger et al., 2010). For example, several agonists of peroxisome proliferator-activated receptors induced the mRNA expressions of several CES1 isoforms in mouse livers (Jones et al., 2013). A moderate increase of CES1 expression was observed in human hepatocytes treated with rifampicin, a prototypical human pregnane $\mathrm{X}$ receptor-activating agent (Shi et al., 2008). An in vivo study with mice suggested that glucose could induce hepatic CES1 expression by stimulating CES1 promoter activity and increasing acetylation of histone 3 and histone 4 in the CES 1 chromatin, indicating a potential role of CES1 in glucose homeostasis $(\mathrm{Xu}$ et al., 2014). Moreover, phenobarbital induced CES1 expression in mouse livers, and the inducibility was more prominent in neonatal mice relative to adult mice (Xiao et al., 2012). Again, a further clinical investigation is needed to determine the impacts of CES1 inducers on the PK and PD of CES1 substrate medications.

Drug-Drug Interactions between CES1 Substrates. In addition to CES1 inhibitors and inducers, concomitant use of multiple CES1 substrate drugs can theoretically impact the substrate metabolism by competitively inhibiting the CES1. This hypothesis has been tested in several studies. An in vitro study suggested trandolapril and enalapril might increase clopidogrel activation (Kristensen et al., 2014). Consistent with the in vitro study, a follow-up retrospective clinical study reported the concomitant use of ACEI prodrugs and clopidogrel increases the risk of clinically important bleeding in patients with myocardial infarction $(n=70,934)(P=0.002)$. The clinical significance of this finding is, however, debatable because the hazard ratio of clinically significant bleeding for patients on concomitant therapy was 1.10 (95\% CI 0.97-1.25) (Kristensen et al., 2014). Another clinical study with the similar design did not report a significant association between the composite cardiovascular outcome and the concomitant use of ACEI prodrugs and clopidogrel in patients with myocardial infarction $(n=45,918)$. The adjusted odds ratios were 0.94 (95\% CI 0.76-1.16) for the perindopril and 0.97 (95\% CI 0.80-1.18) for ramipril, relative to lisinopril, an ACEI not metabolized by CES1 (Cressman et al., 2015).

\section{Disease States Related to CES1}

A prospective clinical study was conducted in monozygotic and dizygotic twin subjects $(62-83$ years) with $(n=48)$ or without $(n=247)$ type 2 diabetes mellitus to examine the association of CES1 with adiposity and metabolic function. CES1 mRNA expression level in adipose tissue was positively associated with body mass index $(P<0.001)$, fasting glucose level $(P=0.002)$, insulin $(P=0.006)$, and triglycerides $(P=0.003)$ (Friedrichsen et al., 2013). Recent studies have also found that CES1 function was positively correlated with increased liver lipid storage and plasma lipid concentrations, indicating that CES1 might be heavily involved in lipid metabolism and is a potential drug target for the treatment of human metabolic disorders (Kaddurah-Daouk et al., 2018; Lian et al., 2018a,b).

\section{Conclusion and Future Directions}

In sum, G143E (rs71647871) is the only clinically significant LOF CES1 variant identified to date, and alcohol is the only potent CES1 inhibitor that significantly affect CES1-mediated drug metabolism both in vivo and in vitro. However, G143E (MAF 2\%-4\%, carrier frequency $4 \%-8 \%$ ) and alcohol-induced DDI are only able to explain a small portion of the interindividual variability in the CES1 function. Previous in vitro studies have demonstrated marked variability of CES1 activity and expression in human liver samples not carrying G143E (Shi et al., 2016a; Wang et al., 2016b). In fact, analysis of the correlation between CES1 expression and activity revealed that the majority of interindividual variability in the CES1 function is due to variation in CES1 protein expression (Wang et al., 2016b).

Unfortunately, the mechanism by which CES1 protein expression is regulated remains largely unexplored. Notably, most of the existing gene expression regulation studies were based upon the measurement of mRNA expression levels. However, increasing evidence suggests that mRNA expression correlates poorly with protein expression for many genes, including CES1 and most DMEs, which could result in false identification of gene expression regulators (Ohtsuki et al., 2012). Recent advances in liquid chromatography tandem mass spectrometry-based proteomics have allowed for accurate CES1 protein quantification. The application of CES1 proteomics in a large set of clinical samples (e.g., human livers) is expected to uncover important factors influencing CES1 expression, such as genetic polymorphisms, disease conditions, inducers, and post-transcriptional modification (Wang et al., 2016a; He et al., 2019); the findings from such research will lead to the development of an individualized pharmacotherapy approach for improving the efficacy and safety of many medications metabolized by CES1.

\section{Authorship Contributions \\ Wrote or contributed to the writing of the manuscript: Her, Zhu.}

\section{References}

Ando Y, Saka H, Ando M, Sawa T, Muro K, Ueoka H, Yokoyama A, Saitoh S, Shimokata K, and Hasegawa Y (2000) Polymorphisms of UDP-glucuronosyltransferase gene and irinotecan toxicity: a pharmacogenetic analysis. Cancer Res 60:6921-6926.

Arena de Souza V, Scott DJ, Nettleship JE, Rahman N, Charlton MH, Walsh MA, and Owens RJ (2015) Comparison of the structure and activity of glycosylated and aglycosylated human carboxylesterase 1. PLoS One 10:e143919.

Bell GH, Griffin WC III, and Patrick KS (2011a) Oral and transdermal DL-methylphenidateethanol interactions in $\mathrm{C} 57 \mathrm{BL} / 6 \mathrm{~J}$ mice: potentiation of locomotor activity with oral delivery. Pharmacol Biochem Behav 100:264-270.

Bell GH, Novak AJ, Griffin WC III, and Patrick KS (2011b) Transdermal and oral dl-methylphenidateethanol interactions in C57BL/6J mice: transesterification to ethylphenidate and elevation of d-methylphenidate concentrations. J Pharm Sci 100:2966-2978.

Boberg M, Vrana M, Mehrotra A, Pearce RE, Gaedigk A, Bhatt DK, Leeder JS, and Prasad B (2017) Age-dependent absolute abundance of hepatic carboxylesterases (CES1 and CES2) by LC-MS/MS proteomics: application to PBPK modeling of oseltamivir in vivo pharmacokinetics in infants. Drug Metab Dispos 45:216-223.

Bozzi LM, Mitchell BD, Lewis JP, Ryan KA, Herzog WR, O'Connell JR, Horenstein RB, Shuldiner AR, and Yerges-Armstrong LM (2016) The pharmacogenomics of anti-platelet intervention (PAPI) study: variation in platelet response to clopidogrel and aspirin. Curr Vasc Pharmacol 14:116-124.

Briand E, Thomsen R, Linnet K, Rasmussen HB, Brunak S, and Taboureau O (2019) Combined ensemble docking and machine learning in identification of therapeutic agents with potential inhibitory effect on human CES1. Molecules 24:2747.

Bruxel EM, Salatino-Oliveira A, Genro JP, Zeni CP, Polanczyk GV, Chazan R, Rohde LA and Hutz MH (2013) Association of a carboxylesterase 1 polymorphism with appetite reduction in children and adolescents with attention-deficit/hyperactivity disorder treated with methylphenidate. Pharmacogenomics $J$ 13:476-480.

Chaturvedi S (2004) The seventh report of the joint national committee on prevention, detection, evaluation, and treatment of high blood pressure (JNC 7): is it really practical? Natl Med J India 17:227.

COTEMPLA XR-ODT(TM) (2017) Product Information: COTEMPLA XR-ODT(TM) oral extended-release disintegrating tablets, methylphenidate oral extended-release disintegrating tablets. Neos Therapeutics IGP, Grand Prairie, TX.

Cressman AM, Macdonald EM, Fernandes KA, Gomes T, Paterson JM, Mamdani MM, and Juurlink DN; Canadian Drug Safety Effectiveness Research Network (CDSERN) (2015) A population-based study of the drug interaction between clopidogrel and angiotensin converting enzyme inhibitors. Br J Clin Pharmacol 80:662-669.

Crow JA, Herring KL, Xie S, Borazjani A, Potter PM, and Ross MK (2010) Inhibition of carboxylesterase activity of THP1 monocytes/macrophages and recombinant human carboxylesterase 1 by oxysterols and fatty acids. Biochim Biophys Acta 1801:31-41.

Dahlgren FS, Shay DK, Izurieta HS, Forshee RA, Wernecke M, Chillarige Y, Lu Y, Kelman JA and Reed C (2018) Evaluating oseltamivir prescriptions in Centers for Medicare and Medicaid Services medical claims records as an indicator of seasonal influenza in the United States. Influenza Other Respir Viruses 12:465-474.

DiPiro JT (2017) Pharmacotherapy: A Pathophysiologic Approach, McGraw-Hill Education, New York.

Dolinsky VW, Gilham D, Alam M, Vance DE, and Lehner R (2004) Triacylglycerol hydrolase: role in intracellular lipid metabolism. Cell Mol Life Sci 61:1633-1651. 
Foti RS and Dalvie DK (2016) Cytochrome P450 and non-cytochrome P450 oxidative metabolism: contributions to the pharmacokinetics, safety, and efficacy of xenobiotics. Drug Metab Dispos 44:1229-1245.

Foye WO, Lemke TL, and Williams DA (2013) Foye's Principles of Medicinal Chemistry, Wolters Kluwer Health/Lippincott Williams \& Wilkins, Philadelphia.

Friedrichsen M, Poulsen P, Wojtaszewski J, Hansen PR, Vaag A, and Rasmussen HB (2013) Carboxylesterase 1 gene duplication and mRNA expression in adipose tissue are linked to obesity and metabolic function. PLoS One 8:e56861.

Fukami T, Nakajima M, Maruichi T, Takahashi S, Takamiya M, Aoki Y, McLeod HL, and Yoko $\mathrm{T}$ (2008) Structure and characterization of human carboxylesterase 1A1, 1A2, and $1 \mathrm{~A} 3$ genes. Pharmacogenet Genomics 18:911-920.

Fukami T and Yokoi T (2012) The emerging role of human esterases. Drug Metab Pharmacokinet 27:466-477

Geshi E, Kimura T, Yoshimura M, Suzuki H, Koba S, Sakai T, Saito T, Koga A, Muramatsu M, and Katagiri T (2005) A single nucleotide polymorphism in the carboxylesterase gene is associated with the responsiveness to imidapril medication and the promoter activity. Hypertens Res 28:719-725.

Ghosh S, Zhao B, Bie J, and Song J (2010) Macrophage cholesteryl ester mobilization and atherosclerosis. Vascul Pharmacol 52:1-10.

Griffin WC III, McGovern RW, Bell GH, Randall PK, Middaugh LD, and Patrick KS (2013) Interactive effects of methylphenidate and alcohol on discrimination, conditioned place preference and motor coordination in C57BL/6J mice. Psychopharmacology (Berl) 225:613-625.

Griffin WC III, Novak AJ, Middaugh LD, and Patrick KS (2010) The interactive effects of methylphenidate and ethanol on ethanol consumption and locomotor activity in mice. Pharmacol Biochem Behav 95:267-272.

Hamzic S, Kummer D, Milesi S, Mueller D, Joerger M, Aebi S, Amstutz U, and Largiader CR (2017) Novel genetic variants in carboxylesterase 1 predict severe early-onset capecitabinerelated toxicity. Clin Pharmacol Ther 102:796-804.

Hasin DS (2018) US epidemiology of cannabis use and associated problems. Neuropsychopharmacology 43:195-212.

He B, Shi J, Wang X, Jiang H, and Zhu HJ (2019) Label-free absolute protein quantification with data-independent acquisition. J Proteomics 200:51-59.

Heal DJ and Pierce DM (2006) Methylphenidate and its isomers: their role in the treatment of attention-deficit hyperactivity disorder using a transdermal delivery system. CNS Drugs 20: 713-738.

Hines RN, Simpson PM, and McCarver DG (2016) Age-dependent human hepatic carboxylesterase 1 (CES1) and carboxylesterase 2 (CES2) postnatal ontogeny. Drug Metab Dispos 44:959-966.

Hosokawa M, Furihata T, Yaginuma Y, Yamamoto N, Watanabe N, Tsukada E, Ohhata Y, Kobayashi K, Satoh T, and Chiba K (2008) Structural organization and characterization of the regulatory element of the human carboxylesterase (CES1A1 and CES1A2) genes. Drug Metab Pharmacokinet 23:73-84.

Hu ZY, Edginton AN, Laizure SC, and Parker RB (2014) Physiologically based pharmacokinetic modeling of impaired carboxylesterase-1 activity: effects on oseltamivir disposition [published correction appears in Clin Pharmacokinet (2014) 53:959]. Clin Pharmacokinet 53:825-836.

Imai T, Taketani M, Shii M, Hosokawa M, and Chiba K (2006) Substrate specificity of carboxylesterase isozymes and their contribution to hydrolase activity in human liver and small inestine. Drug Metab Dispos 34:1734-1741.

Innocenti F, Undevia SD, Iyer L, Chen PX, Das S, Kocherginsky M, Karrison T, Janisch L, Ramírez J, Rudin CM, et al. (2004) Genetic variants in the UDP-glucuronosyltransferase 1A1 gene predict the risk of severe neutropenia of irinotecan. J Clin Oncol 22:1382-1388.

Jewell C, Bennett P, Mutch E, Ackermann C, and Williams FM (2007) Inter-individual variability in esterases in human liver. Biochem Pharmacol 74:932-939.

Jiang XL, Samant S, Lewis JP, Horenstein RB, Shuldiner AR, Yerges-Armstrong LM, Peletier LA Lesko LJ, and Schmidt S (2016) Development of a physiology-directed population pharmacokinetic and pharmacodynamic model for characterizing the impact of genetic and demographic factors on clopidogrel response in healthy adults. Eur J Pharm Sci 82:64-78.

Johnson KA, Barry E, Lambert D, Fitzgerald M, McNicholas F, Kirley A, Gill M, Bellgrove MA, and Hawi Z (2013) Methylphenidate side effect profile is influenced by genetic variation in the attention-deficit/hyperactivity disorder-associated CES1 gene. J Child Adolesc Psychopharmacol 23:655-664.

Jones RD, Taylor AM, Tong EY, and Repa JJ (2013) Carboxylesterases are uniquely expressed among tissues and regulated by nuclear hormone receptors in the mouse. Drug Metab Dispos 41 $40-49$.

Kaddurah-Daouk R, Hankemeier T, Scholl EH, Baillie R, Harms A, Stage C, Dalhoff KP, Jürgens G, Taboureau O, Nzabonimpa GS, et al.; INDICES Consortium; ; Pharmacometabolomics Research Network (2018) Pharmacometabolomics informs about pharmacokinetic profile of methylphenidate. CPT Pharmacometrics Syst Pharmacol 7:525-533.

Kristensen KE, Zhu HJ, Wang X, Gislason GH, Torp-Pedersen C, Rasmussen HB, Markowitz JS, and Hansen PR (2014) Clopidogrel bioactivation and risk of bleeding in patients cotreated with angiotensin-converting enzyme inhibitors after myocardial infarction: a proof-of-concept study. Clin Pharmacol Ther 96:713-722.

Laizure SC, Herring V, Hu Z, Witbrodt K, and Parker RB (2013) The role of human carboxylesterases in drug metabolism: have we overlooked their importance? Pharmacotherapy 33: 210-222.

Laizure SC, Parker RB, Herring VL, and Hu ZY (2014) Identification of carboxylesterasedependent dabigatran etexilate hydrolysis. Drug Metab Dispos 42:201-206.

Lewis JP, Horenstein RB, Ryan K, O'Connell JR, Gibson Q, Mitchell BD, Tanner K, Chai S, Bliden KP, Tantry US, et al. (2013) The functional G143E variant of carboxylesterase 1 is associated with increased clopidogrel active metabolite levels and greater clopidogrel response. Pharmacogenet Genomics 23:1-8.

Lian J, Bahitham W, Panigrahi R, Nelson R, Li L, Watts R, Thiesen A, Lemieux MJ, and Lehner R (2018a) Genetic variation in human carboxylesterase CES1 confers resistance to hepatic steatosis. Biochim Biophys Acta Mol Cell Biol Lipids 1863:688-699.

Lian J, Nelson R, and Lehner R (2018b) Carboxylesterases in lipid metabolism: from mouse to human. Protein Cell 9:178-195.

Mahmoudpour SH, Asselbergs FW, de Keyser CE, Souverein PC, Hofman A, Stricker BH, de Boer A, and Maitland-van der Zee AH (2015) Change in prescription pattern as a potential marker for adverse drug reactions of angiotensin converting enzyme inhibitors. Int J Clin Pharm 37 $1095-1103$.
Mehta SR, Yusuf S, Peters RJ, Bertrand ME, Lewis BS, Natarajan MK, Malmberg K, Rupprecht H, Zhao F, Chrolavicius S, et al.; Clopidogrel in Unstable angina to prevent Recurrent Events trial (CURE) Investigators (2001) Effects of pretreatment with clopidogrel and aspirin followed by long-term therapy in patients undergoing percutaneous coronary intervention: the PCI-CURE study. Lancet 358:527-533.

Nelveg-Kristensen KE, Madsen MB, Torp-Pedersen C, Køber L, Egfjord M, Hansen T, Pedersen O, Rasmussen HB, and Hansen PR (2016) Prognostic impact of carboxylesterase 1 gene variants in patients with congestive heart failure treated with angiotensin-converting enzyme inhibitors. Pharmacogenet Genomics 26:169-177.

Nemoda Z, Angyal N, Tarnok Z, Gadoros J, and Sasvari-Szekely M (2009) Carboxylesterase 1 gene polymorphism and methylphenidate response in ADHD. Neuropharmacology 57: $731-733$

Oh J, Lee S, Lee H, Cho JY, Yoon SH, Jang IJ, Yu KS, and Lim KS (2017) The novel carboxylesterase 1 variant c.662A $>\mathrm{G}$ may decrease the bioactivation of oseltamivir in humans. PLoS One 12:e0176320.

Ohtsuki S, Schaefer O, Kawakami H, Inoue T, Liehner S, Saito A, Ishiguro N, Kishimoto W, Ludwig-Schwellinger E, Ebner T, et al. (2012) Simultaneous absolute protein quantification of transporters, cytochromes P450, and UDP-glucuronosyltransferases as a novel approach for the characterization of individual human liver: comparison with mRNA levels and activities. Drug Metab Dispos 40:83-92.

Paré G, Eriksson N, Lehr T, Connolly S, Eikelboom J, Ezekowitz MD, Axelsson T, Haertter S, Oldgren J, Reilly P, et al. (2013) Genetic determinants of dabigatran plasma levels and their relation to bleeding. Circulation 127:1404-1412.

Parker RB, Hu ZY, Meibohm B, and Laizure SC (2015) Effects of alcohol on human carboxylesterase drug metabolism. Clin Pharmacokinet 54:627-638.

Patrick KS, Straughn AB, Minhinnett RR, Yeatts SD, Herrin AE, DeVane CL, Malcolm R, Janis GC, and Markowitz JS (2007) Influence of ethanol and gender on methylphenidate pharmacokinetics and pharmacodynamics. Clin Pharmacol Ther 81:346-353.

Patrick KS, Straughn AB, Reeves OT III, Bernstein H, Bell GH, Anderson ER, and Malcolm RJ (2013) Differential influences of ethanol on early exposure to racemic methylphenidate compared with dexmethylphenidate in humans. Drug Metab Dispos 41:197-205.

Qian Y, Wang X, and Markowitz JS (2019) In vitro inhibition of carboxylesterase 1 by major cannabinoids and selected metabolites. Drug Metab Dispos 47:465-472.

Rautio J, Kärkkäinen J, and Sloan KB (2017) Prodrugs - recent approvals and a glimpse of the pipeline. Eur J Pharm Sci 109:146-161.

Rautio J, Kumpulainen H, Heimbach T, Oliyai R, Oh D, Järvinen T, and Savolainen J (2008) Prodrugs: design and clinical applications. Nat Rev Drug Discov 7:255-270.

Rhoades JA, Peterson YK, Zhu HJ, Appel DI, Peloquin CA, and Markowitz JS (2012) Prediction and in vitro evaluation of selected protease inhibitor antiviral drugs as inhibitors of carboxylesterase 1: a potential source of drug-drug interactions. Pharm Res 29:972-982.

Roe MT, Armstrong PW, Fox KAA, White HD, Prabhakaran D, Goodman SG, Cornel JH, Bhat DL, Clemmensen P, Martinez F, et al.; TRILOGY ACS Investigators (2012) Prasugrel versus clopidogrel for acute coronary syndromes without revascularization. $N$ Engl $J$ Med 367: 1297-1309.

Ross MK, Streit TM, and Herring KL (2010) Carboxylesterases: dual roles in lipid and pesticide metabolism. J Pestic Sci 35:257-264.

Sai K, Saito Y, Tatewaki N, Hosokawa M, Kaniwa N, Nishimaki-Mogami T, Naito M, Sawada J, Shirao K, Hamaguchi T, et al. (2010) Association of carboxylesterase 1A genotypes with irinotecan pharmacokinetics in Japanese cancer patients. Br J Clin Pharmacol 70:222-233.

Satoh T and Hosokawa M (2006) Structure, function and regulation of carboxylesterases. Chem Biol Interact 162:195-211.

Schubert I, Köster I, and Lehmkuhl G (2010) The changing prevalence of attention-deficit/hyperactivity disorder and methylphenidate prescriptions: a study of data from a random sample of insurees of the AOK Health Insurance Company in the German State of Hesse, 2000-2007. Dtsch Arztebl Int 107:615-621.

Scott SA, Sangkuhl K, Stein CM, Hulot JS, Mega JL, Roden DM, Klein TE, Sabatine MS, Johnson JA, and Shuldiner AR; Clinical Pharmacogenetics Implementation Consortium (2013) Clinical Pharmacogenetics Implementation Consortium guidelines for CYP2C19 genotype and clopidogrel therapy: 2013 update. Clin Pharmacol Ther 94:317-323.

Shah VP and Amidon GL (2014) G.L. Amidon, H. Lennernas, V.P. Shah, and J.R. Crison. A theoretical basis for a biopharmaceutic drug classification: the correlation of in vitro drug product dissolution and in vivo bioavailability, Pharm Res 12, 413-420, 1995--backstory of BCS. AAPS J 16:894-898

Shi D, Yang D, Prinssen EP, Davies BE, and Yan B (2011) Surge in expression of carboxylesterase 1 during the post-neonatal stage enables a rapid gain of the capacity to activate the anti-influenza prodrug oseltamivir. J Infect Dis 203:937-942.

Shi D, Yang J, Yang D, LeCluyse EL, Black C, You L, Akhlaghi F, and Yan B (2006) Antiinfluenza prodrug oseltamivir is activated by carboxylesterase human carboxylesterase 1 , and the activation is inhibited by antiplatelet agent clopidogrel. J Pharmacol Exp Ther 319:1477-1484

Shi D, Yang J, Yang D, and Yan B (2008) Dexamethasone suppresses the expression of multiple rat carboxylesterases through transcriptional repression: evidence for an involvement of the glucocorticoid receptor. Toxicology 254:97-105.

Shi J, Wang X, Eyler RF, Liang Y, Liu L, Mueller BA, and Zhu HJ (2016a) Association of oseltamivir activation with gender and carboxylesterase 1 genetic polymorphisms. Basic Clin Pharmacol Toxicol 119:555-561.

Shi J, Wang X, Nguyen JH, Bleske BE, Liang Y, Liu L, and Zhu HJ (2016b) Dabigatran etexilate activation is affected by the CES1 genetic polymorphism G143E (rs71647871) and gender. Biochem Pharmacol 119:76-84.

Shi J, Wang X, Nguyen J, Wu AH, Bleske BE, and Zhu HJ (2016c) Sacubitril is selectively activated by carboxylesterase 1 (CES1) in the liver and the activation is affected by CES1 genetic variation. Drug Metab Dispos 44:554-559.

Shmyr D, Van der Merwe V, Yakiwchuk E, Barry A, and Kosar L (2017) Triple antithrombotic therapy for atrial fibrillation and coronary stents. Can Fam Physician 63:375-381.

Singh S, Barghoorn J, Bagdonas A, Adler J, Treanor J, Kinnersley N, and Ward P (2003) Clinical benefits with oseltamivir in treating influenza in adult populations: results of a pooled and subgroup analysis. Clin Drug Investig 23:561-569.

Stage C, Jürgens G, Guski LS, Thomsen R, Bjerre D, Ferrero-Miliani L, Lyauk YK, Rasmussen HB, and Dalhoff K; INDICES Consortium (2017a) The impact of CES1 genotypes on the pharmacokinetics of methylphenidate in healthy Danish subjects. Br J Clin Pharmacol 83: 1506-1514. 
Stage C, Jürgens G, Guski LS, Thomsen R, Bjerre D, Ferrero-Miliani L, Lyauk YK, Rasmussen HB, and Dalhoff K; INDICES Consortium (for members of this consortium-see Supplementum) (2017b) The pharmacokinetics of enalapril in relation to CES1 genotype in healthy Danish volunteers. Basic Clin Pharmacol Toxicol 121:487-492.

Staudinger JL, Xu C, Cui YJ, and Klaassen CD (2010) Nuclear receptor-mediated regulation of carboxylesterase expression and activity. Expert Opin Drug Metab Toxicol 6:261-271.

Steinhubl SR, Berger PB, Mann JT III, Fry ET, DeLago A, Wilmer C, and Topol EJ; CREDO Investigators. Clopidogrel for the Reduction of Events During Observation (2002) Early and sustained dual oral antiplatelet therapy following percutaneous coronary intervention: a randomized controlled trial [published correction appears in JAMA (2003) 289:987]. JAMA 288: 2411-2420.

Suzaki Y, Uemura N, Hosokawa M, and Ohashi K (2013a) Gly143Glu polymorphism of the human carboxylesterase1 gene in an Asian population. Eur J Clin Pharmacol 69:735-736.

Suzaki Y, Uemura N, Takada M, Ohyama T, Itohda A, Morimoto T, Imai H, Hamasaki H, Inano A, Hosokawa M, et al. (2013b) The effect of carboxylesterase 1 (CES1) polymorphisms on the pharmacokinetics of oseltamivir in humans. Eur J Clin Pharmacol 69:21-30.

Tanimoto K, Kaneyasu M, Shimokuni T, Hiyama K, and Nishiyama M (2007) Human carboxylesterase $1 \mathrm{~A} 2$ expressed from carboxylesterase $1 \mathrm{~A} 1$ and $1 \mathrm{~A} 2$ genes is a potent predictor of CPT-11 cytotoxicity in vitro. Pharmacogenet Genomics 17:1-10.

Tarkiainen EK, Backman JT, Neuvonen M, Neuvonen PJ, Schwab M, and Niemi M (2012) Carboxylesterase 1 polymorphism impairs oseltamivir bioactivation in humans. Clin Pharmacol Ther 92:68-71.

Tarkiainen EK, Holmberg MT, Tornio A, Neuvonen M, Neuvonen PJ, Backman JT, and Niemi M (2015a) Carboxylesterase 1 c.428G $>$ A single nucleotide variation increases the antiplatelet effects of clopidogrel by reducing its hydrolysis in humans. Clin Pharmacol Ther 97:650-658.

Tarkiainen EK, Tornio A, Holmberg MT, Launiainen T, Neuvonen PJ, Backman JT, and Niemi M (2015b) Effect of carboxylesterase 1 c.428G $>$ A single nucleotide variation on the pharmacokinetics of quinapril and enalapril. Br J Clin Pharmacol 80:1131-1138.

Thomsen R, Rasmussen HB, and Linnet K; INDICES Consortium (2014) In vitro drug metabolism by human carboxylesterase 1: focus on angiotensin-converting enzyme inhibitors. Drug Metab Dispos 42:126-133.

Wallentin L, Becker RC, Budaj A, Cannon CP, Emanuelsson H, Held C, Horrow J, Husted S, James S, Katus H, et al.; PLATO Investigators (2009) Ticagrelor versus clopidogrel in patients with acute coronary syndromes. N Engl J Med 361:1045-1057.

Wang X, Liang Y, Liu L, Shi J, and Zhu HJ (2016a) Targeted absolute quantitative proteomics with SILAC internal standards and unlabeled full-length protein calibrators (TAQSI). Rapid Commun Mass Spectrom 30:553-561.

Wang X, Rida N, Shi J, Wu AH, Bleske BE, and Zhu HJ (2017) A comprehensive functional assessment of carboxylesterase 1 nonsynonymous polymorphisms. Drug Metab Dispos 45:1149-1155.

Wang X, Wang G, Shi J, Aa J, Comas R, Liang Y, and Zhu HJ (2016b) CES1 genetic variation affects the activation of angiotensin-converting enzyme inhibitors. Pharmacogenomics $J$ 16:220-230.

Williams ET, Carlson JE, Lai WG, Wong YN, Yoshimura T, Critchley DJ, and Narurkar M (2011) Investigation of the metabolism of rufinamide and its interaction with valproate. Drug Metab Lett 5:280-289.

Wiviott SD, Braunwald E, McCabe CH, Montalescot G, Ruzyllo W, Gottlieb S, Neumann FJ, Ardissino D, De Servi S, Murphy SA, et al.; TRITON-TIMI 38 Investigators (2007) Prasugrel versus clopidogrel in patients with acute coronary syndromes. $N$ Engl J Med 357: 2001-2015.

Xiao D, Chen YT, Yang D, and Yan B (2012) Age-related inducibility of carboxylesterases by the antiepileptic agent phenobarbital and implications in drug metabolism and lipid accumulation. Biochem Pharmacol 84:232-239.

Xiao FY, Luo JQ, Liu M, Chen BL, Cao S, Liu ZQ, Zhou HH, Zhou G, and Zhang W (2017) Effect of carboxylesterase $1 \mathrm{~S} 75 \mathrm{~N}$ on clopidogrel therapy among acute coronary syndrome patients. Sci Rep 7:1-6.

Xie C, Ding X, Gao J, Wang H, Hang Y, Zhang H, Zhang J, Jiang B, and Miao L (2014) The effects of CES1A2 A(-816)C and CYP2C19 loss-of-function polymorphisms on clopidogrel response variability among Chinese patients with coronary heart disease. Pharmacogenet Genomics 24:204-210.

Xu J, Yin L, Xu Y, Li Y, Zalzala M, Cheng G, and Zhang Y (2014) Hepatic carboxylesterase 1 is induced by glucose and regulates postprandial glucose levels. PLoS One 9:e109663.
Yamada S, Richardson K, Tang M, Halaschek-Wiener J, Cook VJ, Fitzgerald JM, Elwood K, Marra F, and Brooks-Wilson A (2010) Genetic variation in carboxylesterase genes and susceptibility to isoniazid-induced hepatotoxicity. Pharmacogenomics $J$ 10:524-536.

Yancy CW, Jessup M, Bozkurt B, Butler J, Casey DE Jr, Colvin MM, Drazner MH, Filippatos GS, Fonarow GC, Givertz MM, et al. (2017) 2017 ACC/AHA/HFSA focused update of the 2013 ACCF/AHA guideline for the management of heart failure: a report of the American College of Cardiology/American Heart Association Task Force on Clinical Practice Guidelines and the Heart Failure Society of America. Circulation 136:e137-e161.

Yang D, Pearce RE, Wang X, Gaedigk R, Wan YJY, and Yan B (2009) Human carboxylesterases HCE1 and HCE2: ontogenic expression, inter-individual variability and differential hydrolysis of oseltamivir, aspirin, deltamethrin and permethrin. Biochem Pharmacol 77:238-247.

Yoshimura M, Kimura T, Ishii M, Ishii K, Matsuura T, Geshi E, Hosokawa M, and Muramatsu M (2008) Functional polymorphisms in carboxylesterase1A2 (CES1A2) gene involves specific protein 1 (Sp1) binding sites. Biochem Biophys Res Commun 369:939-942.

Zhao B, Song J, St Clair RW, and Ghosh S (2007) Stable overexpression of human macrophage cholesteryl ester hydrolase results in enhanced free cholesterol efflux from human THP1 macrophages. Am J Physiol Cell Physiol 292:C405-C412.

Zhao Z, Li X, Sun S, Mei S, Ma N, Miao Z, Zhao M, and Peng S (2016) Impact of genetic polymorphisms related to clopidogrel or acetylsalicylic acid pharmacology on clinical outcome in Chinese patients with symptomatic extracranial or intracranial stenosis. Eur J Clin Pharmacol 72:1195-1204.

Zhu HJ, Appel DI, Jiang Y, and Markowitz JS (2009a) Age- and sex-related expression and activity of carboxylesterase 1 and 2 in mouse and human liver. Drug Metab Dispos 37:1819-1825.

Zhu HJ, Appel DI, Johnson JA, Chavin KD, and Markowitz JS (2009b) Role of carboxylesterase 1 and impact of natural genetic variants on the hydrolysis of trandolapril. Biochem Pharmacol 77: $1266-1272$.

Zhu HJ, Appel DI, Peterson YK, Wang Z, and Markowitz JS (2010) Identification of selected therapeutic agents as inhibitors of carboxylesterase 1: potential sources of metabolic drug interactions. Toxicology 270:59-65.

Zhu HJ, Langaee TY, Gong Y, Wang X, Pepine CJ, Cooper-DeHoff RM, Johnson JA, and Markowitz JS (2016) CES1P1 variant $-816 \mathrm{~A}>\mathrm{C}$ is not associated with hepatic carboxylesterase 1 expression and activity or antihypertensive effect of trandolapril. Eur J Clin Pharmacol 72:681-687.

Zhu HJ and Markowitz JS (2009) Activation of the antiviral prodrug oseltamivir is impaired by two newly identified carboxylesterase 1 variants. Drug Metab Dispos 37:264-267.

Zhu HJ, Patrick KS, and Markowitz JS (2011) Enantiospecific determination of DLmethylphenidate and DL-ethylphenidate in plasma by liquid chromatography-tandem mass spectrometry: application to human ethanol interactions. J Chromatogr B Analyt Technol Biomed Life Sci 879:783-788.

Zhu HJ, Patrick KS, Straughn AB, Reeves OT III, Bernstein H, Shi J, Johnson HJ, Knight JM, Smith AT, Malcolm RJ, et al. (2017) Ethanol interactions with dexmethylphenidate and dlmethylphenidate spheroidal oral drug absorption systems in healthy volunteers. J Clin Psychopharmacol 37:419-428.

Zhu HJ, Patrick KS, Yuan HJ, Wang JS, Donovan JL, DeVane CL, Malcolm R, Johnson JA, Youngblood GL, Sweet DH, et al. (2008) Two CES1 gene mutations lead to dysfunctional carboxylesterase 1 activity in man: clinical significance and molecular basis. Am J Hum Genet 82:1241-1248

Zhu HJ, Wang X, Gawronski BE, Brinda BJ, Angiolillo DJ, and Markowitz JS (2013) Carboxylesterase 1 as a determinant of clopidogrel metabolism and activation. J Pharmacol Exp Ther 344:665-672.

Zou J-J, Chen S-L, Fan H-W, Tan J, He B-S, and Xie H-G (2014) CES1A -816C as a genetic marker to predict greater platelet clopidogrel response in patients with percutaneous coronary intervention. J Cardiovasc Pharmacol 63:178-183.

Address correspondence to: Dr. Hao-Jie Zhu, Department of Clinical Pharmacy, University of Michigan College of Pharmacy, 428 Church Street, Room 4565 NUB, Ann Arbor, Ml 48109-1065. E-mail: hjzhu@med.umich.edu 